\title{
Investigation of hole cleaning parameters using computational fluid dynamics in horizontal and deviated wells
}

\author{
Nekkhil Mishra \\ West Virginia University
}

Follow this and additional works at: https://researchrepository.wvu.edu/etd

\section{Recommended Citation}

Mishra, Nekkhil, "Investigation of hole cleaning parameters using computational fluid dynamics in horizontal and deviated wells" (2007). Graduate Theses, Dissertations, and Problem Reports. 4320. https://researchrepository.wvu.edu/etd/4320

This Thesis is protected by copyright and/or related rights. It has been brought to you by the The Research Repository @ WVU with permission from the rights-holder(s). You are free to use this Thesis in any way that is permitted by the copyright and related rights legislation that applies to your use. For other uses you must obtain permission from the rights-holder(s) directly, unless additional rights are indicated by a Creative Commons license in the record and/ or on the work itself. This Thesis has been accepted for inclusion in WVU Graduate Theses, Dissertations, and Problem Reports collection by an authorized administrator of The Research Repository @ WVU. For more information, please contact researchrepository@mail.wvu.edu. 


\title{
INVESTIGATION OF HOLE CLEANING PARAMETERS USING COMPUTATIONAL FLUID DYNAMICS IN HORIZONTAL AND DEVIATED WELLS
}

\author{
Nekkhil Mishra \\ A Thesis Submitted to the College of \\ Engineering and Mineral Resources \\ at West Virginia University \\ in partial fulfillment of the requirements \\ for the degree of \\ Master of Science \\ in \\ Petroleum and Natural Gas Engineering \\ Dr. H. Ilkin Bilgesu, Ph.D., Chairperson \\ Prof. Samuel Ameri, M.S. \\ Dr. K. Aminian, Ph.D. \\ Dr. Daniel E. Della-Giustina, Ph.D.
}

Department of Petroleum and Natural Gas Engineering

Morgantown, West Virginia

2007

Keywords: Cuttings Transport, CFD, Hole Cleaning, Horizontal Wellbores 


\section{ABSTRACT \\ INVESTIGATION OF HOLE CLEANING PARAMETERS USING COMPUTATIONAL FLUID DYNAMICS IN HORIZONTAL AND DEVIATED WELLS}

\section{Nekkhil Mishra}

The need for technologies to reduce cost and improve recovery from existing hydrocarbon reservoirs is well established. One of the most effective methods of cost reduction relies on improvement of drilling technologies. Particularly, understanding the parameters that control hole cleaning is beneficial especially in both horizontal and deviated wells. For this purpose, a section of casing-drill pipe annulus section was simulated using Computational Fluid Dynamics to determine the effects of fluid velocity, cutting size, rate of penetration, drill pipe rotation and inclination angle in deviated wells. The Eulerian Model Simulations were conducted at steady state and the results of the data collected for maximum cutting concentrations in the annulus were graphically analyzed. Formation of cutting beds is noticed near the entry section of the annulus and the transport of the cuttings in the annular section occurs in the form of stratified flow. Fluid flow rate, angle of inclination and rate of penetration have a major impact on cutting concentrations and proper prediction of these parameters are important to avoid formation of cutting beds. It is also noted that drillpipe rotation can enhance cutting transport but it generally has a greater effect on smaller sized particles. 


\section{ACKNOWLEDGEMENT}

This project was initiated by Dr. H. Ilkin Bilgesu, to investigate the possibility of using Computational Fluid Dynamics as a tool to study the parameters involved in hole cleaning. To fully understand this project, some technical knowledge of Computational Fluid Dynamics is useful.

I strongly believe that the presented work is a product of combined efforts, in terms of inspiration, support, encouragement, contributed by a number of people. I would like to express my gratitude towards my advisor Dr. H. Ilkin Bilgesu for his continuous advice, support and encouragement throughout this entire work. The complete freedom to work independently, that he gave to me, helped me explore various areas of research during my Master's degree.

I am very grateful to Prof. Samuel Ameri for his assistance and encouragement during my stay at WVU. I would like to thank Dr. K. Aminian and Dr. Daniel E. DellaGiustina for serving as a committee member.

I would like to mention Beverly Matheny, our Administrative Assistant, for her help she provided during my stay here. 


\section{TABLE OF CONTENTS}

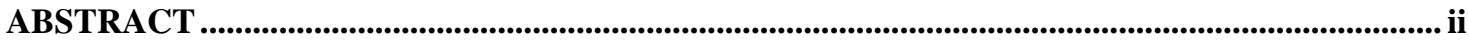

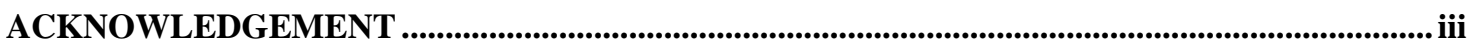

TABLE OF CONTENTS ......................................................................................................................... iv

LIST OF FIGURES ....................................................................................................................................... vi

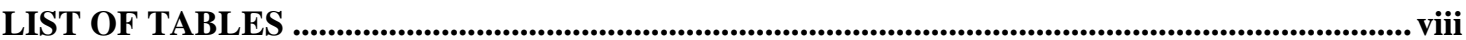

NOMENCLATURE

\section{CHAPTER 1}

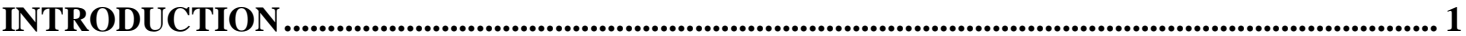

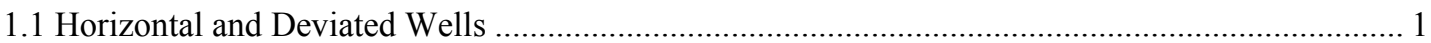

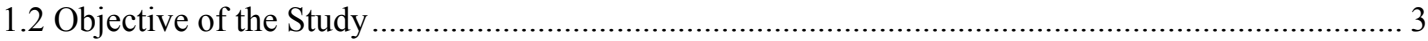

\section{CHAPTER 2}

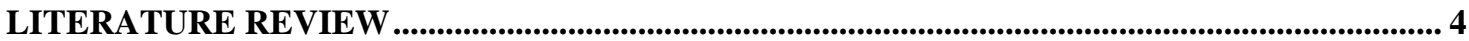

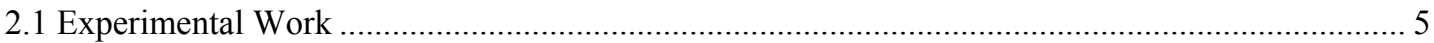

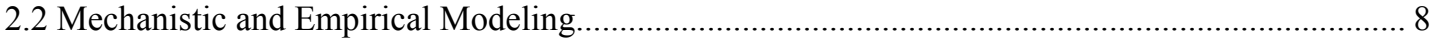

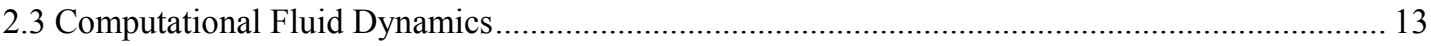

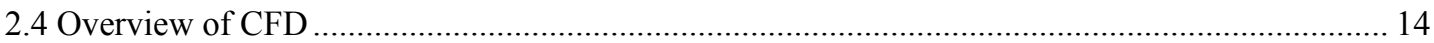

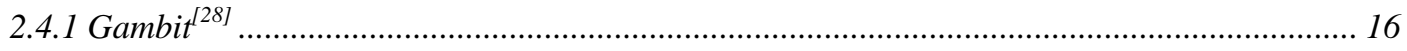

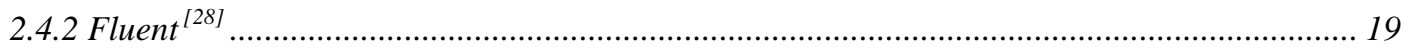

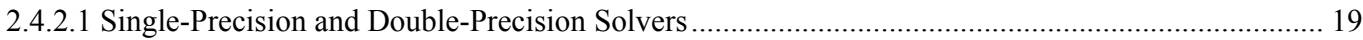

2.4.2.2 Numerical Scheme ................................................................................................................ 19

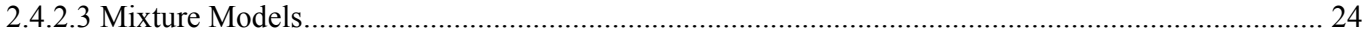

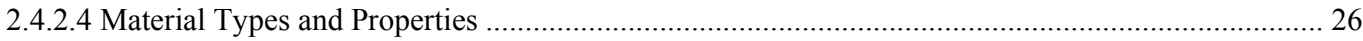

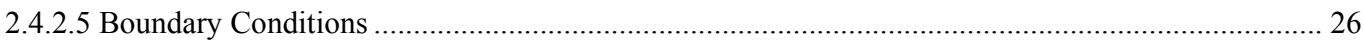




\section{CHAPTER 3}

MODEL SETUP

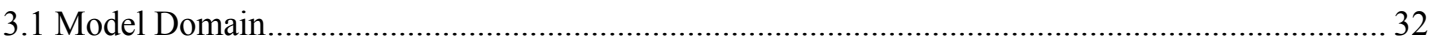

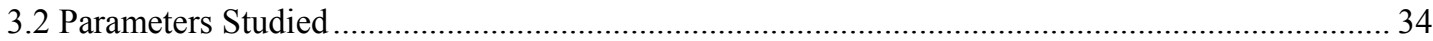

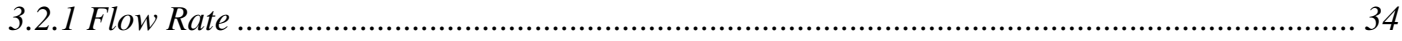

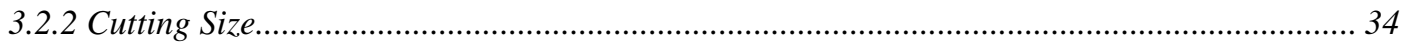

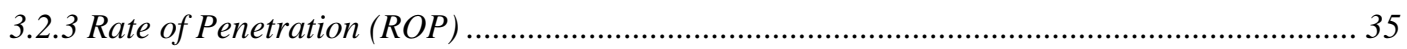

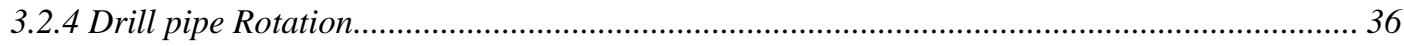

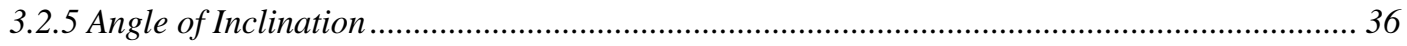

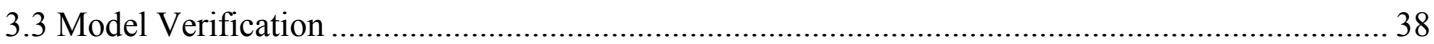

\section{CHAPTER 4}

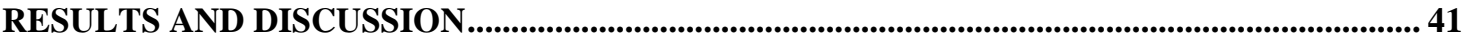

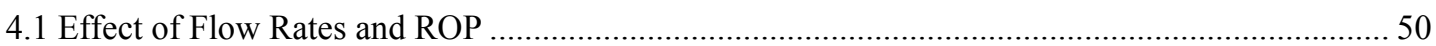

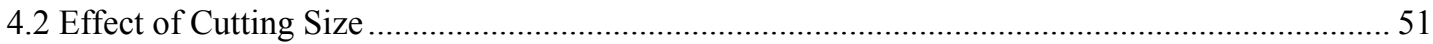

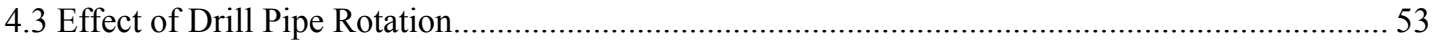

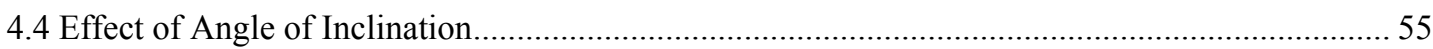

\section{CHAPTER 5}

CONCLUSIONS AND RECOMMENDATIONS .................................................................................. 56

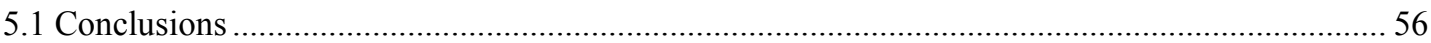

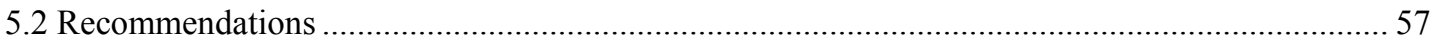

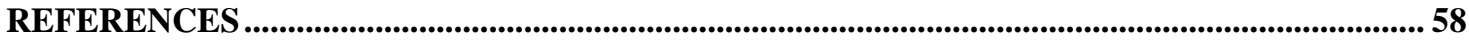

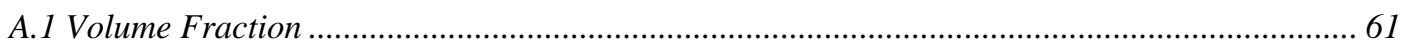

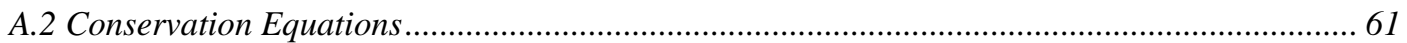

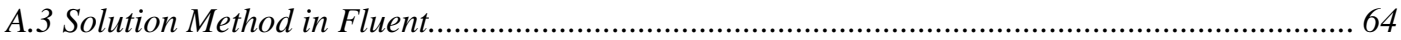




\section{LIST OF FIGURES}

Figure 1: Flow pattern for solid liquid flow in horizontal annulus. ${ }^{[2]}$............................................. 4

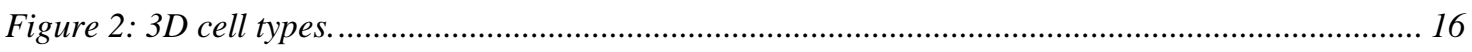

Figure 3: Annular section of pipe showing the source and non source faces........................................ 17

Figure 4: Mesh generated for the annular section............................................................................. 18

Figure 5: Steps taken in preparing mesh for Fluent...................................................................... 18

Figure 6: Procedure for segregated solution method. ............................................................................ 21

Figure 7: Procedure for the coupled solver approach............................................................................. 23

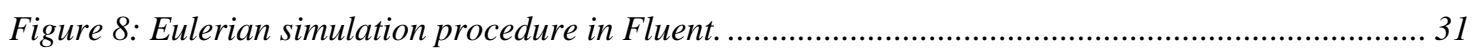

Figure 9: Grid size of each cell in the annular section........................................................................... 32

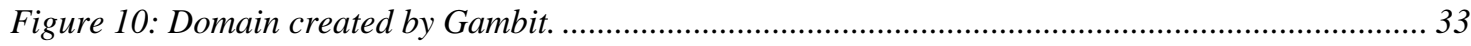

Figure 11: Forces acting due to deviation in the well.............................................................................. 36

Figure 12: Comparison of model predicted pressure drop values across annulus with lab data............ 40

Figure 13: Comparison of cutting concentrations from model prediction with lab data.......................... 40

Figure 14: Variation of cutting concentration with flow rate for $3 \mathrm{~mm}$ particles. ................................... 42

Figure 15: Variation of cutting concentration with flow rate for $8 \mathrm{~mm}$ particles...................................... 42

Figure 16: Variation of cutting concentration with flow rate for $3 \mathrm{~mm}$ particles.................................... 44

Figure 17: Variation of cutting concentration with flow rate for $8 \mathrm{~mm}$ Particles.................................... 45

Figure 18: Variation of cutting concentration with flow rate for $3 \mathrm{~mm}$ Particles.................................... 46

Figure 19: Variation of cutting concentration with. flow rate for $3 \mathrm{~mm}$ particles. .................................. 47

Figure 20: Variation of cutting concentration with flow rate for a deviated well..................................... 48

Figure 21: Variation of cutting concentration with. flow rate for a deviated well.................................... 49

Figure 22: Effect of cutting sizes in horizontal wells without drill pipe rotation..................................... 51

Figure 23: Effect of cutting sizes in horizontal wells at 30 RPM......................................................... 52

Figure 24: Effect of cutting sizes in horizontal wells at 60 RPM.......................................................... 52 
Figure 25: Variation of cutting concentration with drill pipe rotation for a horizontal well,

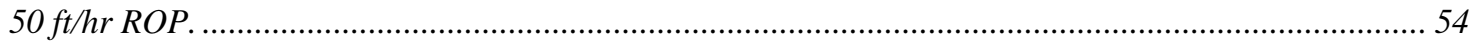

Figure 26: Variation of cutting concentration with drill pipe rotation for horizontal well,

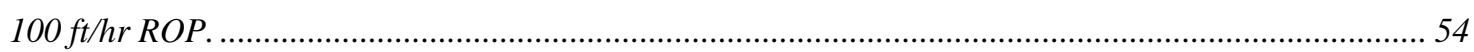




\section{LIST OF TABLES}

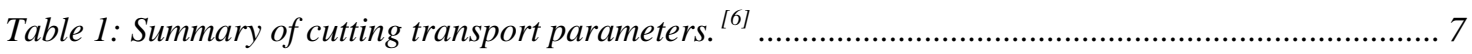

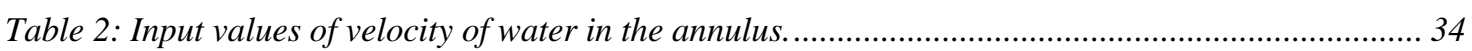

Table 3: Input velocity of phase-2 (cuttings) at $4 \%$ volume fraction. ...................................................... 35

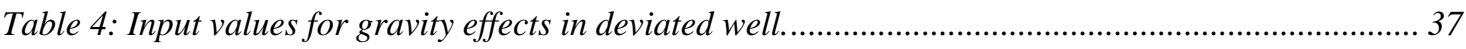

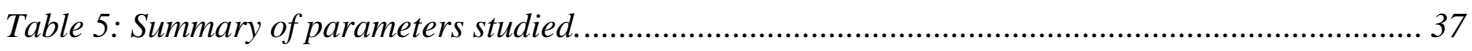

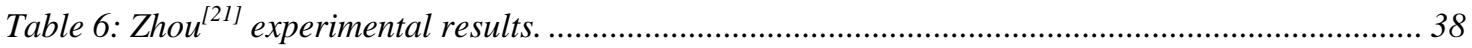

Table 7: Concentration change percentages for particles in horizontal wells without

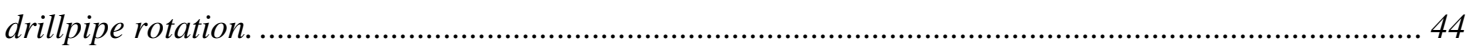

Table 8: Concentration change percentages for 3mm particles in horizontal wells with

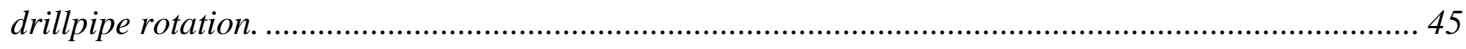




\title{
NOMENCLATURE
}

\author{
A - Area $\left(\mathrm{m}^{2}\right)$ \\ C - Concentration (\%) \\ $D_{h}-\quad$ Hydraulic diameter (m) \\ $\vec{F} \quad-\quad$ Force vector $(\mathrm{N})$ \\ $\vec{g} \quad$ - Acceleration due to gravity $\left(\mathrm{m} / \mathrm{s}^{2}\right)$ \\ $\dot{m} \quad-\quad$ Mass flow rate $(\mathrm{kg} / \mathrm{s})$ \\ $m$ - Mass $(\mathrm{kg})$ \\ Re - Reynolds Number (dimensionless) \\ ROP - Rate of penetration ( $\mathrm{ft} / \mathrm{hr})$ \\ t $\quad-\quad$ Time $(\mathrm{s})$ \\ T.I - Turbulence intensity (\%) \\ $\mathrm{V} \quad$ - Volume $\left(\mathrm{m}^{3}\right)$ \\ $V_{\text {cut }}-\quad$ Velocity of cuttings $(\mathrm{m} / \mathrm{s})$ \\ $v$ - Velocity magnitude $(\mathrm{m} / \mathrm{s})$ \\ $\vec{v} \quad$ - Overall velocity vector $(\mathrm{m} / \mathrm{s})$ \\ $\alpha \quad$ - Volume fraction (dimensionless) \\ q - primary phase \\ $\mu \quad-\quad$ Dynamic viscosity (cP)
}




$$
\begin{aligned}
& \rho-\text { Density }\left(\mathrm{kg} / \mathrm{m}^{3}\right) \\
& =\quad-\quad \text { Stress-strain tensor }(\mathrm{Pa})
\end{aligned}
$$




\section{CHAPTER 1 \\ INTRODUCTION}

\subsection{Horizontal and Deviated Wells}

Enhancement of drilling technology is an effective technique both, to reduce cost and enhance recovery from reservoirs. Horizontal and directional drilling provides significant production improvement over vertical wells through increased reservoir contact. It's more cost effective, creates less drilling waste and provides access to thin and tight reservoirs that are inaccessible to vertical drilling.

As horizontal wellbores get longer and deeper, and as practices such as extended reach drilling become more common, hole cleaning can be an increasingly difficult and different challenge from vertical wells. In an inclined well, cuttings settle vertically, but the fluid velocity has a reduced vertical component. Particles settle quickly and have less distance to travel before they hit the borehole wall. Here, the velocities are negligible and particles tend to deposit in the annulus leading to the formation of contiguous beds. Significant reduction of transport capacity occurs in horizontal wells. Inefficient hole cleaning and formation of beds lead to problems such as premature bit wear, high torque and drag, stuck pipe and slow drilling rates which increase drill time and costs.

The major parameters which affect hole cleaning in an annulus can be divided into three

different groups ${ }^{[1]}$. The first group consists of the fluid parameters such as fluid density, 
fluid viscosity and fluid flow rate. The second group consists of cutting parameters which include cutting density, cutting shape and size and cutting concentration. The third group consists of the operational parameters i.e. the angle of inclination, pipe rotation speed and eccentricity in the hole. Research into these cutting transportation parameters and their effects can lead to prediction of carrying capacity of fluids and therefore facilitating the optimum design of directional wells.

Computational Fluid Dynamics (CFD) is a computer program widely used in the characterization of complex geometries and fluid behavior. Experimental research work such as building of a flow loop can take considerable time and money. CFD can be used to model the unsteady state mass, momentum and energy exchange that occurs in an annular section under simulated downhole conditions of temperature and pressure. This research initiative therefore has been undertaken to conduct the specific parametric study of fluid flow through the annulus using built in Eulerian Model in CFD. 


\subsection{Objective of the Study}

The objective of this study is to model and investigate the steady state analysis of effects of the specific hole cleaning parameters (flow rate, cutting size, rate of penetration (ROP), drillpipe rotation and inclination angles) using CFD. The approach undertaken to achieve these goals is as follows:

- To conduct an extensive literature review of hole cleaning experimental and modeling works to facilitate better understanding of the existing works and obtain realistic parameter values to include in the model setup.

- To comprehend and be able to implement the steady state simulation of downhole cleaning conditions using CFD.

- To verify the CFD simulations using existing literature data.

- To simulate using the Eulerian Model in CFD under steady state conditions and analyze of specific hole cleaning parameter that effect cutting transportation. 


\section{CHAPTER 2}

\section{LITERATURE REVIEW}

Real time data from on site locations is impossible to collect and analyze with cutting transport parameters. Hence, researchers ${ }^{[3,4,5,6]}$ started building large scale flow loops to conduct experiments to observe and investigate the variables that affect cutting transportation. The observations of these experiments suggested the existence of different flow patterns based on the hole cleaning parameters. (Figure 1)

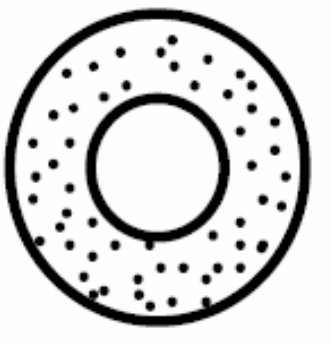

a. SUSPENDED SYMMETRIC

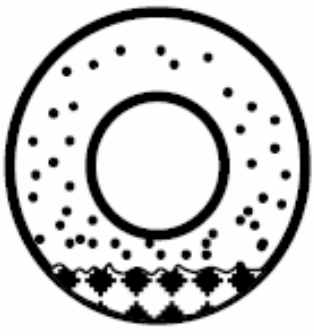

c. MOVING BED

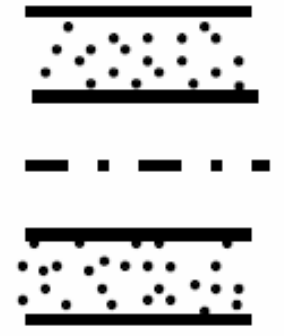

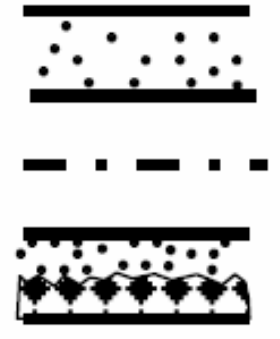$$
\text { BED }
$$
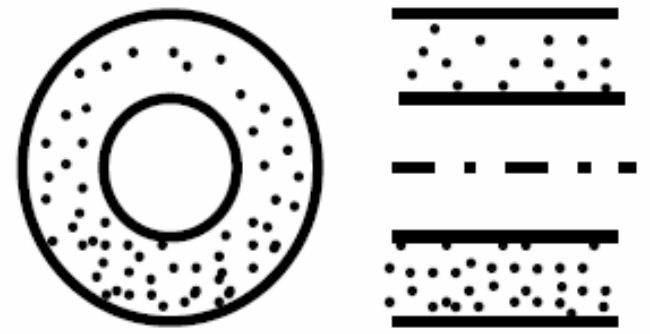

b. SUSPENDED ASYMMETRIC
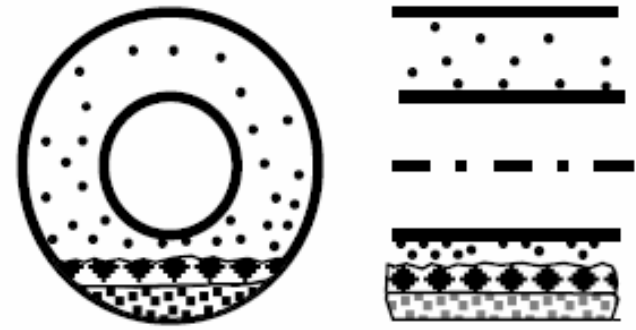

d. STATIONARY - MOVING BED

Figure 1: Flow pattern for solid liquid flow in horizontal annulus. ${ }^{[2]}$

Cutting transport problems in horizontal conduits occur only when moving bed or stationary-moving bed patterns are observed. The parameter values that lead to bed 
formations are the ones that are of importance and the ones that are studied in the literature. These experimental works mostly give us general correlations and rules of thumbs (ranges of parameters) to avoid the formation of the bed.

Normally cutting transport modeling techniques utilize the general strategy of layered modeling and full numerical solutions in the given cross-sectional area. Most of these models try and represent the experimentally verified phenomenon by conservation laws of mass, momentum and energy. Usually, theses models are used to predict cutting bed heights, pressure drop, and transport velocities based on these different parameters. There has been evolution of these models over the years and its necessary to examine all these models to verify that CFD's modeling capability are comparable and in most cases superior to the models present out there.

\subsection{Experimental Work}

Ziedler $^{[3]}$ conducted one of the pioneering studies of cutting transportation. A laboratory setup consisting of a 15 feet long, 3.5 inch inner diameter glass tube was employed to study and correlate the settling velocity of particles based on measurable properties. This correlation was based on the drag coefficient-Reynolds number plots. He used a 65 feet long 8-1/2 inch casing with 4-1/2 inch drillpipe to derive correlations for drilled particle recovery fractions and study the effects of various parameters such as flow rate, fluid viscosity and inner pipe rotation on transport mechanisms. It was observed that turbulent flow and drillpipe rotation increased the cutting transport rate. 
Tormen et. al. ${ }^{[4]}$ performed a comprehensive study of steady state cutting transportation in inclined wells by means of a flow loop. The study was conducted with a 5 inch 40 feet long transparent section. He investigated numerous angles of inclination, flow rates, drillpipe rotations and pipe hole eccentricities. He identified visually the occurrence of cutting or sliding beds based on various parameters. It was reported that the major factors that should be considered in directional wells are fluid velocity, hole inclination, and mud and rheological properties.

Okranjni and Azar ${ }^{[5]}$ studied specifically the effects of field measured mud rheological properties like apparent viscosity, plastic viscosity, yield value and gel strength in inclined wells. Since different muds could have the same rheological property, a ratio of yield point (YP) to plastic viscosity (PV) was additionally used to distinguish the muds. The study was done on the same flow loop as Tormen et. al. ${ }^{[4]}$ using 15 different types of mud systems including water. They noted that in the turbulent regime, the transport capacity of mud was found to be independent of its rheological properties. The transport is affected most by momentum forces which is mainly a function of mud density. Also in horizontal wells, it was deduced that the turbulence would be a positive factor in the cleaning of the annulus while the rotation of the drillpipe didn't actually contribute to the cleaning of the bed, but it inhibited the formation of the bed. They lastly provided some field guidelines for directional well drilling.

Sifferman and Becker ${ }^{[6]}$ performed experiments using an 8 inch 60 foot long flow loop. They studied the effects of annular velocity, mud density, mud rheology, mud type, 
cutting size, rate of penetration (ROP), drillpipe rotary speed, drillpipe eccentricity, drillpipe diameter, and hole angles $\left(45^{\circ}\right.$ to $90^{\circ}$ from the vertical). The experiment was split into three phases to be able to conduct a statistical analysis of the drilling parameters and validate the existence of interactions between them. Their results are summarized in the Table 1.

\begin{tabular}{|l|l|}
\hline Effects & Factors \\
\hline Major & Mud weight \\
& Annular mud velocity \\
& Hole angle \\
& Drillpipe rotation \\
\hline Moderate & Rheology \\
& Cuttings size \\
& Eccentricity \\
\hline Minor/insignificant & Feed concentration (ROP) \\
& Mud type \\
& Drillipipe size \\
\hline
\end{tabular}

Table 1: Summary of cutting transport parameters. ${ }^{[6]}$

Duan et. al. ${ }^{[7]}$ concentrated on studying transport of smaller size cuttings ranging from 1.3 $\mathrm{mm}$ to $7 \mathrm{~mm}$. The experiments were conducted with an 8 inch 100 foot long field size flow loop. Transport of smaller cuttings was studied with water and polymeric fluids. From the experiments correlations were developed to predict annular cutting concentration and dimensional bed height. It was observed that smaller cuttings were harder to transport in water as compared to larger ones, however, easier to transport when polyacrylic co-polymer (PAC) solutions were used. Also, pipe rotation and rheology were the important parameters in smaller cutting transportation. 


\section{$\underline{2.2 \text { Mechanistic and Empirical Modeling }}$}

Gravignet and Sobey ${ }^{[8]}$ developed one of the first cuttings transport mechanistic/two layered models for non-Newtonian drilling fluids in an eccentric annulus. This model was based on previous models in slurry transportation. They compared their model with the experimental results of Okranjni and Azar ${ }^{[5]}$. They assumed that the model consisted to two distinct layers, a cuttings bed of compacted solids near the bottom of the pipe and clear mud above it. The saltation mechanism was not included in the transport of the cutting bed i.e. the bed was assumed to slide up the annulus and it didn't take into account pipe rotation. Their model estimated bed thickness as a function of mud flow rate, $\mathrm{ROP}$, inclination and annular geometry by relating the interfacial sheer stress to fluid and bed velocities. The model suggested a minimum flow rate to avoid formation of a cuttings bed and suggest a wall frictional factor of 0.2 .

Martins and Santana ${ }^{[9]}$ presented a two-layer stratified model of solid non-Newtonian fluid mixtures in horizontal and near horizontal eccentric annuli. This model was superior to Gravignet and Sobey ${ }^{[8]}$ as it assumed that the top layer contained a homogeneous mixture of mud and cuttings. The model was developed using conservation laws of mass and linear momentum and constitutive relations which describe the interactions between the two phases and the phases and the walls. The particle concentration in the heterogeneous layer was determined by solving the diffusion equation. Bed heights, average solids concentration and frictional loss calculations were based on the flow pattern present. This approach was based on the work done in slurry flow of pipes by 
Doron and Barnea ${ }^{[10]}$. Later works by Martins and Santana ${ }^{[1]]}$ included drillpipe rotation effects, use of different rheological models to characterize the fluid flow and the introduction of a permeability equation to describe flow through a bed.

Pilehvari et. al. ${ }^{[12]}$ carried out a review of cutting transport in horizontal wellbores. The advancement in cutting transportation research is summarized and suggestions are made for much more work on turbulent flows of non-Newtonian fluids, effects of drillpipe rotation, comprehensive solid-liquid flow model and the development of a hole cleaning monitoring system that receives all the available relevant data in real time for quick analysis and determining the borehole status.

Besides mechanistic models, there have been a number of empirical predictive correlations $^{[13,14,15]}$ which are based on experimental studies. They predict critical transport fluid velocity, average cutting travel velocity and annular cutting concentration under most given sets of drilling operating conditions. These simple sets of algorithms can easily be implemented by computer systems and might give a set of predictive guidelines in the field.

Santana et. al. ${ }^{[16]}$ tested and verified the validity of using the correlation based solid-fluid interfacial frictional factor in two-layered models. Investigation of the possible choice of rheological model (Bingham, Power Law, Casson, Herschell-Bulkley and Robetson Stiff) was undertaken. It was stated that though choice of the model has significant impact on hole cleaning predictions, it was concluded that, for field cases, Bingham and Cassons 
model was inaccurate. They also tested the accuracy of the popular assumption of no slip conditions between the solid and liquid in the homogeneous layer and showed that it produced reasonable accurate results.

Kamp and Rivero ${ }^{[17]}$ developed a two-layered model for near horizontal wellbores. It consisted of a stationary or moving bed below a layer of heterogeneous cutting suspension. It assumed that there was no significant slip velocity difference between the particles and the mud. It took into account cuttings settling and resuspension, but not the vertical motion of the particles in the liquid. This simplified the model by assuming the liquid and cuttings had the same density hence not taking into account pressure and temperature affects. The model predicted thickness of the uniform bed as a function of mud flow rate, cuttings diameter, mud viscosity, pipe eccentricity and other properties of the flow. The results of the model were compared to a previous correlation based model. This model over predicted carrying capacity at a given flow rate. The closure terms in the model were based on experimental results. The author suggested possible improvements to the model including solving separate momentum equations for the solids and mud in the suspension layer.

Martins et. al. ${ }^{[18]}$ presented and implemented an inventive time dependent cutting transport model for extended reach wells. They accounted for the additional volume of solids generated by wellbore instabilities. The transient model is based on previously developed two-layered models except that the mass and momentum balance equations were non-steady state. A finite volume approach, with staggered mesh for pressure and 
velocity is used to solve the system of four partial differential equations. They showed that steady-state conditions are not reached even after a considerable amount of time.

Cho et. al. ${ }^{[19]}$ developed a three-segment hydraulic model for cuttings transport in horizontal and deviated wells. The model considered the following layers: 1) a stationary bed of cuttings in the low side of the borehole, 2) moving bed layer above the stationary bed and 3) a heterogeneous suspension layer at the top. They modeled three segments to deal with the well deviation: horizontal segment $\left(60-90^{\circ}\right.$ deviation), transient segment $\left(30-60^{\circ}\right.$ deviation $)$ and vertical segment $\left(0-30^{\circ}\right.$ deviation). For every segment they set up continuity equations and momentum equations. They analyzed the interface interaction using the correlations. They reported effects of annular velocity, fluid rheology, and angle of inclination on cuttings transport.

Doan et. al. ${ }^{[20]}$ conducted both an experimental investigation and numerical simulation to determine the critical cutting transport velocity in inclined annuli of arbitrary eccentricity. Experiments were carried out with water and three different muds. The behavior of drilled cuttings at both steady state and unsteady-state were recorded by a video camera. The captured images were then analyzed to obtain the velocity profile, the cross-sectional distribution and average velocity of cuttings in the annulus. Results from this experimental investigation were compared against a numerical model. The formulation unlike Martins et. al. ${ }^{[18]}$ allowed for fluid and solid components in the suspension layer to have different velocities, rather than assuming a single velocity for the suspension. Results indicated that the match between experimental and simulated were extremely 
poor at low cuttings injection rates. They concluded that the two-layer model does not adequately describe the interfacial phenomena involved in bed dynamics when the cuttings bed is very thin.

Zhou $^{[21]}$ experimentally studied the cutting transport of particles using aerated muds. He conducted the experiments at elevated temperature and pressure conditions to try and resemble the downhole conditions in wellbores. All the experiments were conducted in a horizontal annulus. He determined the cutting transport ability of aerated muds. He also developed a mechanistic model to determine the gas/liquid injection rates for the effective cutting transport. This computational tool could calculate the pressure loss across the annulus under elevated pressure and temperature conditions. The experiments also included trial runs using water as the transportation fluid. These experimental results were used in the verification of the modeling capabilities of CFD in this thesis. 


\section{$\underline{2.3 \text { Computational Fluid Dynamics }}$}

$\mathrm{CFD}^{[22]}$ has repeatedly been used to improve process plant applications such as pneumatic transport lines, risers, fluidized bed reactors, hoppers etc. CFD gives the flexibility to change the design parameters without expensive hardware change and has a much better turnaround time as compared to experiments. It helps the engineer get to the root of problems and can provide enough information about a flow field where measurements are either difficult or impossible to obtain. The use of CFD as a modeling tool has proven successful in wide areas of petroleum engineering.

Bilgesu et. al. ${ }^{[23]}$ was one of the first researchers to analyze cutting transport parameters using CFD. They studied hole cleaning parameters in both horizontal wells and vertical wells. They used the Discrete Phase Modeling (DPM) capability in Fluent to conduct the analysis in both horizontal and vertical wells. Also they used transport efficiency as a judge of the hole cleaning capabilities. They studied the effect of flow rate, mud weight, viscosity, drilling rate, cutting size and cutting density. The major differences between this study and the previous one are that this work is done using the Eulerian Mixture Modeling capabilities in Fluent. Also the parameters researched in this work are the fluid flow rate, rate of penetration, angle of inclination, drillpipe roatation and cutting size.

Suarez et. al. ${ }^{[24]}$ used CFD simulations to study the performance of a Rotary Gas Separator under two-phase-flow conditions. Water-air mixtures were used as the working 
fluid and gas volume fractions were varied from 10-30\%. The simulations showed adequate segregation for good separation efficiency.

Clem et. al. ${ }^{[25]}$ studied the problem of frac-packing tool erosion in high-profile deepwater well at high pump rates and proppant loads. CFD was used to analyze the various patterns, such as velocity, fluid path, erosion, and sand concentration at high rates. Critical areas were identified for better design and optimization. The results of CFD simulations were verified against full scale results. CFD could not predict the magnitudes of erosion rates but could predict the erosion profiles and velocity magnitudes.

Yusuf $^{[26]}$ used CFD to study the performance of Liquid-Liquid Hydrocylones (LLHC) as an integral part of a down-hole separation system. He used the mixture modeling capability in CFD to study the changes in API oil gravity, flow rates and cyclone geometry.

\section{$\underline{2.4 \text { Overview of CFD }}$}

Computational Fluid Dynamics (CFD) is a part of fluid mechanics that brings to perfection for experimental and analytical fluid engineering. CFD is the science of predicting fluid flow, heat and mass transfer, chemical reactions and related phenomena by solving numerically sets of governing equations. Its capabilities and applications have widely expanded, giving experts in the petroleum industry confidence to use this predictive tool in many applications ranging from drilling to production and post processing. CFD models were applied to simulate the hydrodynamics of complex 
machinery and equipment involving moving parts, erosion, heat transfer, chemical reaction and multiphase flow. Fluent models have been developed and tested with applications such as; drill bits, pumps, static mixers, and distillation trays, separators, packed beds, fluidized beds, reactors and multistage compressors. Fluent solves transport equations needed for each application. It is capable of solving a fast array of complex phenomenon using a storehouse of physical models. We can apply CFD to many problems in petroleum engineering such as ${ }^{[27]}$ :

- Drilling fluids, such as mud (Non-Newtonian viscosity laws).

- Production in oil fields, including flow around down-hole injectors.

- Unsteady and Steady state flow involving two-phase and three-phase (gas-solids, liquid-solids or liquid-liquid mixtures).

- Compressors, pumps, propellers and impellers.

- Flow in refinery equipment such as crude oil desalters and reactors.

- Erosion and other effects of particle-laden flow (comprehensive particle tracking algorithm).

The common procedure to be followed in modeling using CFD is:

- Create the model geometry and grid.

- Set up the solver and physical models.

- Compute and monitor the solution.

- Examine and save the results.

- Consider revision to the numerical or physical model parameters, if necessary. 
Step one of the solution process requires a geometry modeler and grid generator. In our case, we utilized Gambit ${ }^{[28]}$.

\subsection{1 $\mathrm{Gambit}^{[28]}$}

Gambit ${ }^{[28]}$ is a software package designed to help analysts and designers build and mesh models for CFD and other scientific applications. The basic steps involved are building, meshing and assigning zone types to a model. For our model the geometry will be basically two concentric pipes that are subtracted from one another to create an annular section. The second step will be the meshing of the model. Gambit can construct a variety of grids, e.g. conformal block-structured grids, multiblock structured grids, nonconformal grids, and unstructured triangular, tetrahedral, quadrilateral, and hexahedral grids (Figure 2).

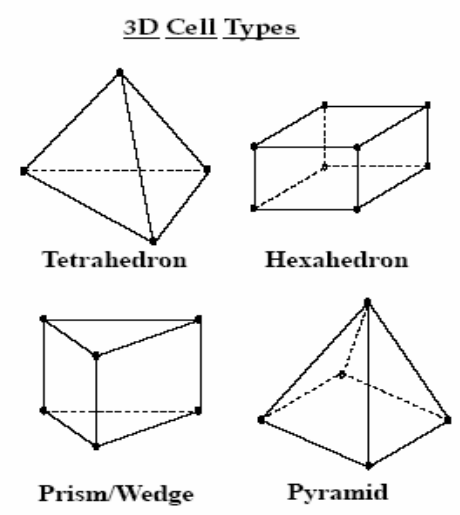

Figure 2: 3D cell types.

The volume meshing scheme of cooper's is used to automatically mesh the annular volume. In the cooper's volume meshing scheme, Gambit treats the volume as consisting of one or more logical cylinders which is composed of two end caps and a barrel. Faces 
that compromise the caps of such cylinders are called source faces (faces A and B in Figure 3); faces that compromise the barrels of the cylinder are called non source faces (faces C and D in Figure 3).

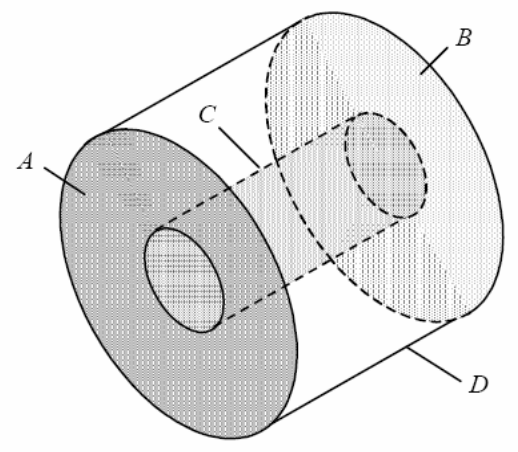

Figure 3: Annular section of pipe showing the source and non source faces.

This coopers meshing results in the Hexahedron Meshing Cell types as shown in Figure 4. The choice of mesh generation is generally based on setup time, computational expense and numerical diffusion. Since the geometry is not complex, a uniform hexahedron scheme becomes more viable. The more the number of meshed cells the greater the computational time so that should also be a factor while meshing. It is one of the primary reasons the mesh created is not very dense for our annulus test section. The last stage in the mesh generation is to specifying the zones types. Zone-type specifications define the physical and operational characteristics of the model at its boundaries and within specific regions of its domain. Boundary-type specifications define the physical and operational characteristics of the model at those topological entities. For example, an INFLOW boundary type specification to a face entity means that material flows into the domain through the specific face. 


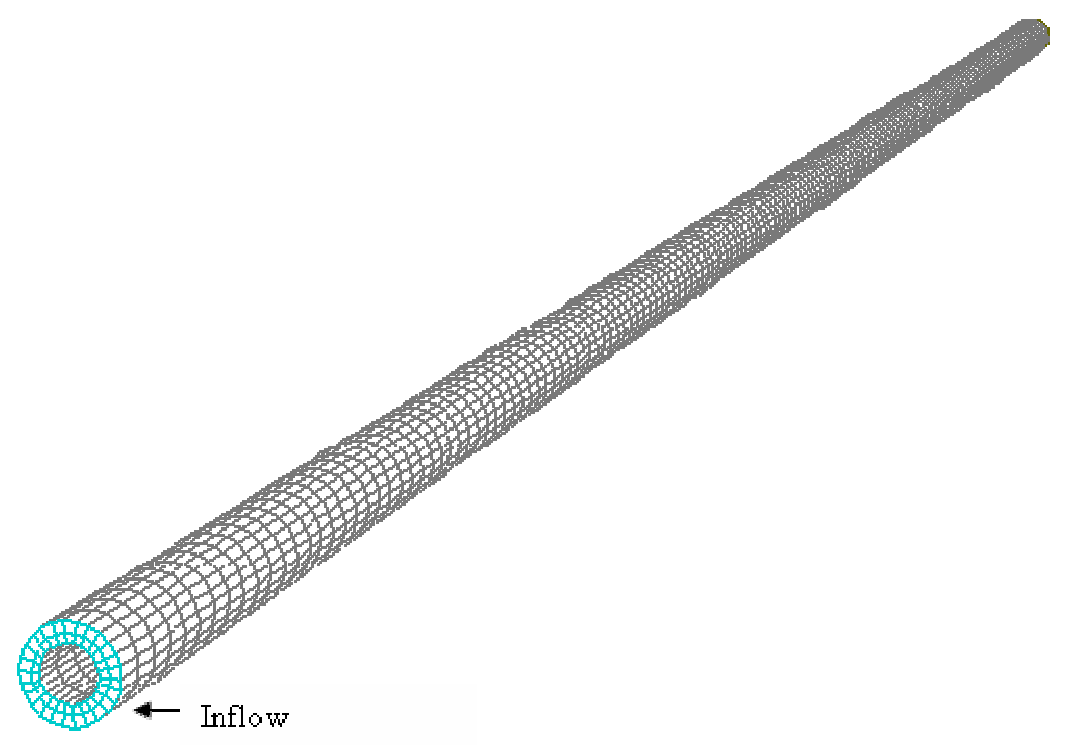

Figure 4: Mesh generated for the annular section.

Each boundary type specification is represented with a different color. The steps in preprocessing are creating the annulus, generating the mesh, examining the mesh quality and assigning boundary types as shown in Figure 5.

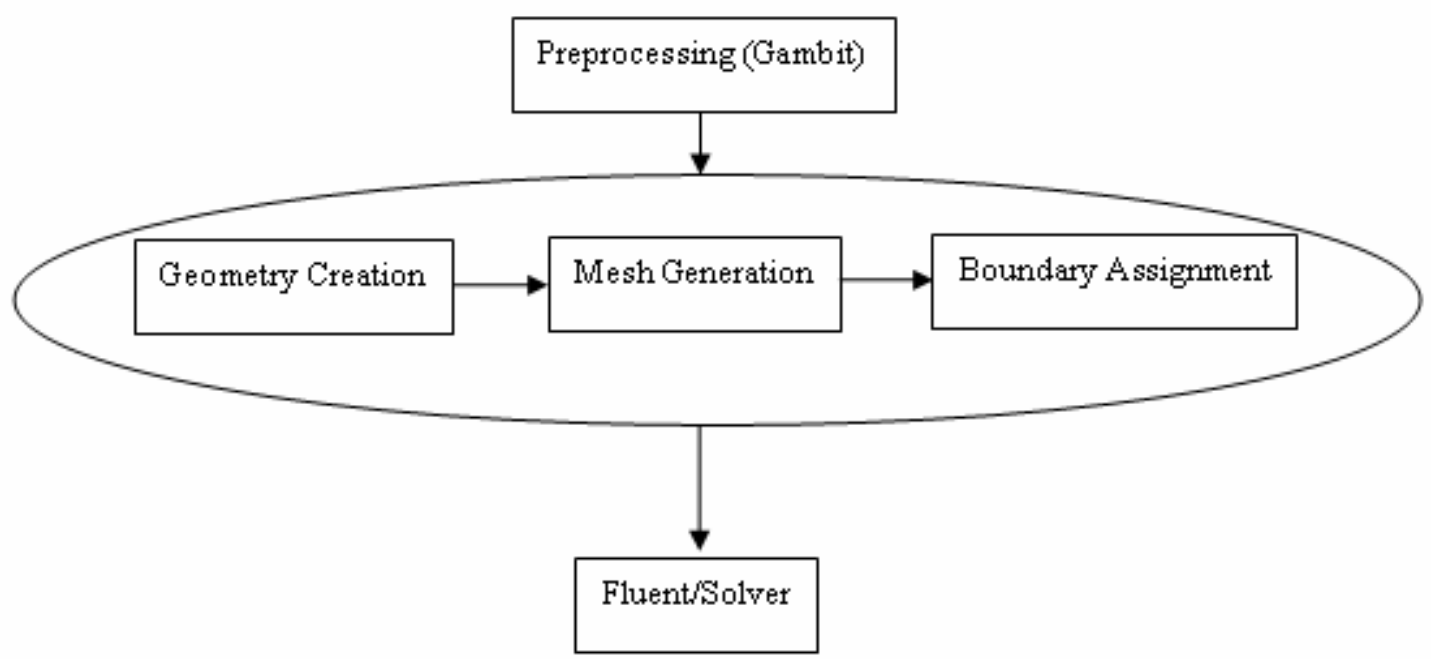

Figure 5: Steps taken in preparing mesh for Fluent. 


\subsubsection{Fluent $^{[28]}$}

Fluent can import grids from various sources. Gambit is the preprocessor used to construct the grid/mesh used in this study.

\subsubsection{Single-Precision and Double-Precision Solvers}

Fluent can use either single-precision or double-precision solvers. For most cases, the single-precision solver will be sufficiently accurate, but certain type of problems may benefit from the use of a double-precision version. If the geometry has features of very disparate length scales (e.g., a very long, thin pipe), single-precision calculations may not be adequate to represent the node coordinates. If the geometry involves multiple enclosures connected via small-diameter pipes (e.g., automotive manifolds), mean pressure levels in all but one of the zones can be quite large. Double-precision calculations may therefore be necessary to resolve the pressure differences that drive the flow, since these will typically be much smaller than the pressure levels. For conjugate problems involving high thermal-conductivity ratios and/or high-aspect-ratio grids, convergence and/or accuracy may be impaired with the single-precision solver, due to inefficient transfer of boundary information.

\subsubsection{Numerical Scheme}

Fluent allows choosing two schemes

- Segregated Solver

- Coupled Solver 
These schemes are used to solve the governing integral equations for the conservation of mass and momentum. They use a control-volume-based technique. First, the volume is divided into discrete control volumes using a computational grid (Gambit). Then the integration of governing equations on the individual control volumes to construct algebraic equations for the discrete dependent variables is done. Last, the linearization of the discretized equations and solution of the resultant linear equation system to yield updated values of dependent variables is carried out.

In the segregated solver approach, the governing equations are solved sequentially (i.e., segregated from one another). Because the governing equations are non-linear (and coupled), several iterations of the solution loop must be performed before a converged solution is obtained. Each iteration consists of the following steps as shown in Figure 6 and also explained as follows:

1. Fluid properties are updated, based on the current solution. (If the calculation has just begun, the fluid properties will be updated based on the initialized solution.)

2. The momentum equations are each solved in turn using current values for pressure and face mass fluxes, in order to update the velocity field.

3. Since the velocities obtained in Step 2 may not satisfy the continuity equation locally, a "Poisson-type" equation for the pressure correction is derived from the continuity equation and the linearized momentum equations. This pressure correction equation is then solved to obtain the necessary corrections to the pressure and velocity fields and the face mass fluxes such that continuity is satisfied. 
4. Where appropriate, equations for scalars such as turbulence, energy, species, and radiation are solved using the previously updated values of the other variables.

5. When interphase coupling is to be included, the source terms in the appropriate continuous phase equations may be updated with a discrete phase trajectory calculation.

6. A check for convergence of the equation set is made.

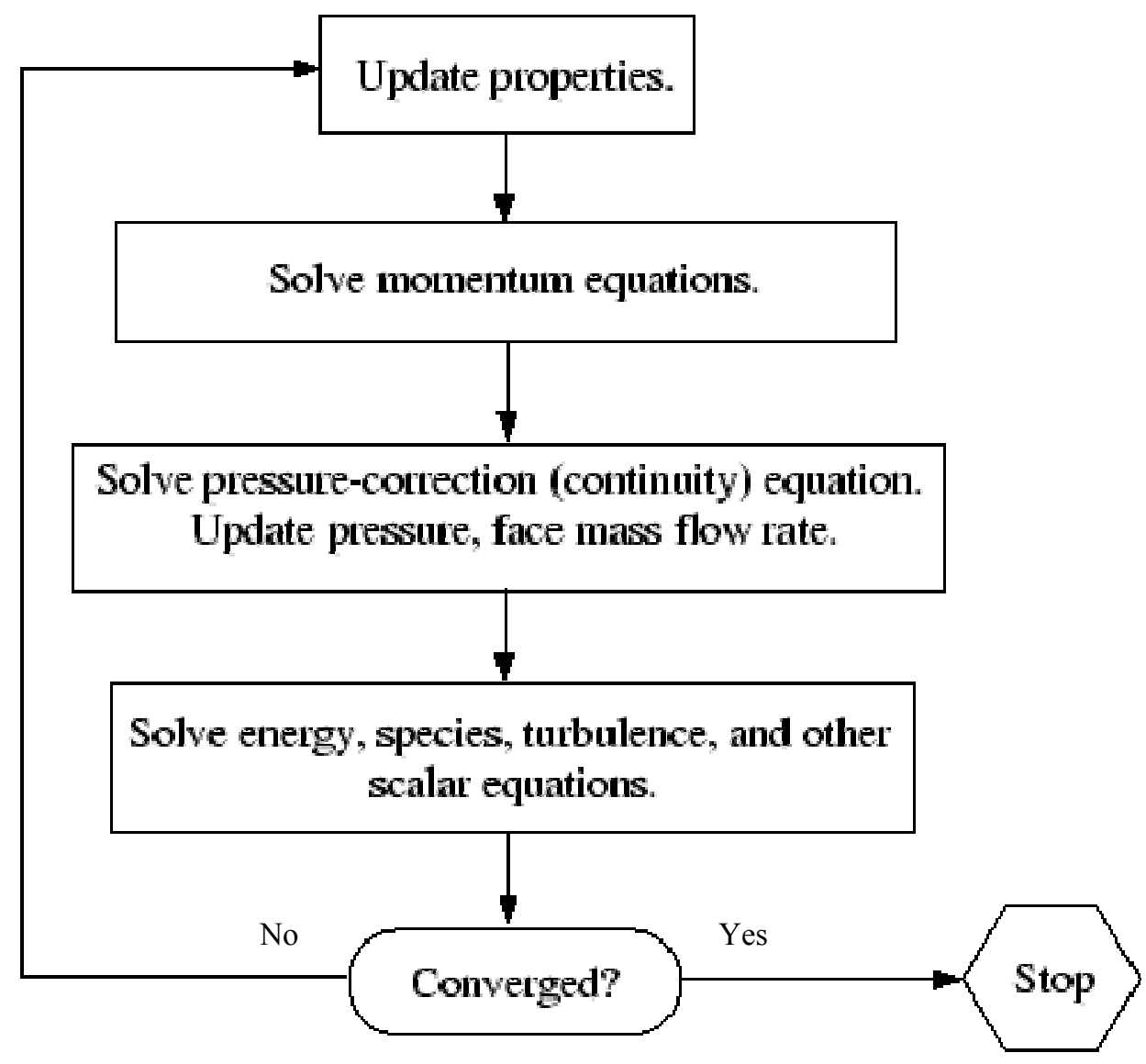

Figure 6: Procedure for segregated solution method.

In the coupled solver approach the governing equations of continuity, momentum, and (where appropriate) energy and species transport are solved simultaneously (i.e., coupled together). Governing equations for additional scalars will be solved sequentially (i.e., 
segregated from one another and from the coupled set). Because the governing equations are non-linear (and coupled), several iterations of the solution loop must be performed before a converged solution is obtained (Figure 7) using the following steps:

1. Fluid properties are updated, based on the current solution. (If the calculation has just begun, the fluid properties will be updated based on the initialized solution.)

2. The continuity, momentum, and (where appropriate) energy and species equations are solved simultaneously.

3. Where appropriate, equations for scalars such as turbulence and radiation are solved using the previously updated values of the other variables.

4. When interphase coupling is to be included, the source terms in the appropriate continuous phase equations may be updated with a discrete phase trajectory calculation.

5. A check for convergence of the equation set is made. 


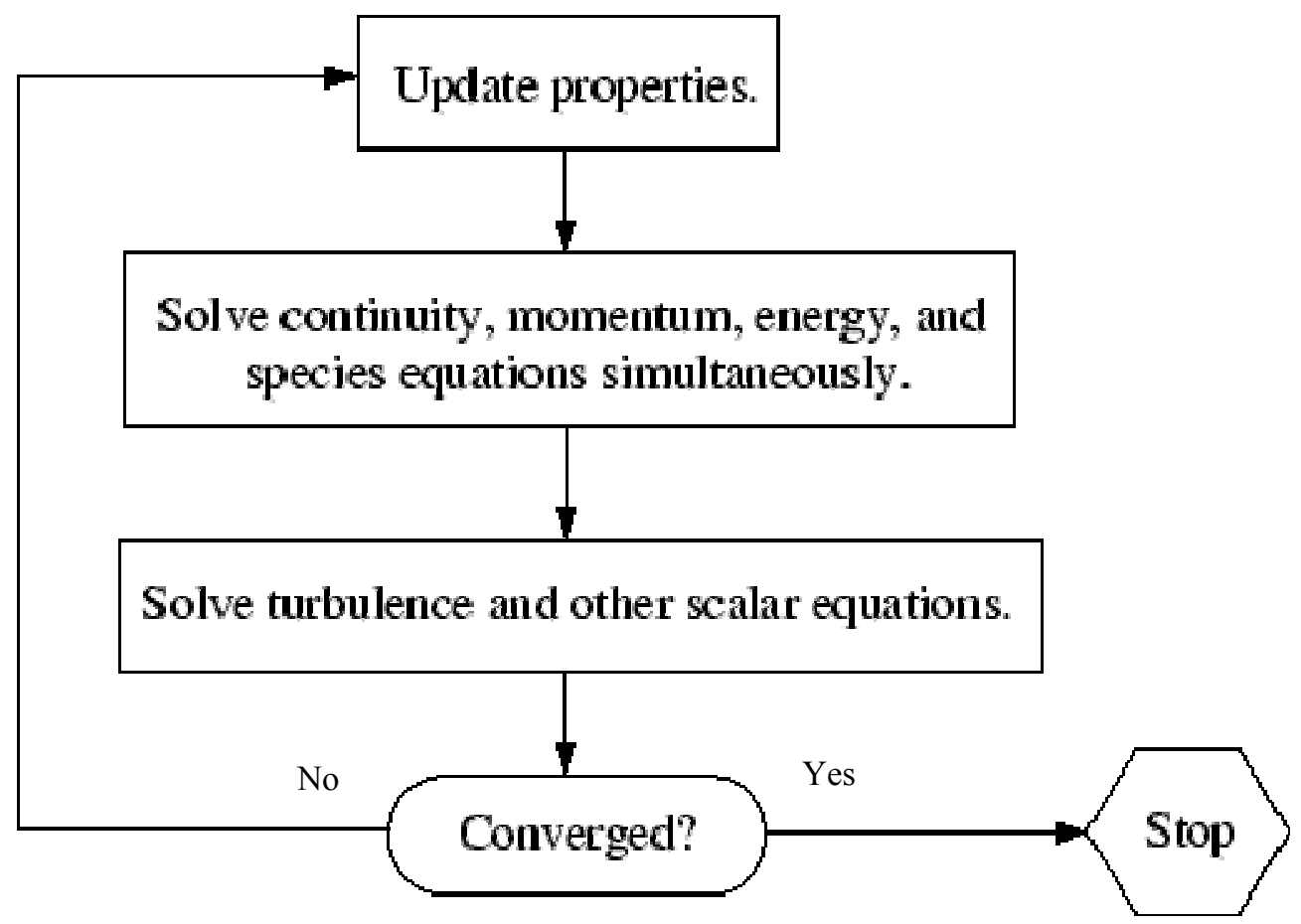

Figure 7: Procedure for the coupled solver approach.

In both, the segregated and coupled solution methods the discrete, non-linear governing equations are linearized to produce a system of equations for the dependent variables in every computational cell. The resultant linear system is then solved to yield an updated flow-field solution. The manner in which the governing equations are linearized may take an "implicit" or "explicit" form with respect to the dependent variable (or set of variables) of interest. By implicit or explicit we mean the following:

- Implicit: For a given variable, the unknown value in each cell is computed using a relation that includes both existing and unknown values from neighboring cells. Therefore each unknown will appear in more than one equation in the system, and these equations must be solved simultaneously to give the unknown quantities. 
- Explicit: For a given variable, the unknown value in each cell is computed using a relation that includes only existing values. Therefore each unknown will appear in only one equation in the system and the equations for the unknown value in each cell can be solved one at a time to give the unknown quantities.

\subsubsection{Mixture Models}

Since our domain consists of fluid and particles, we will use one of the mixture models built in Fluent. In multiphase flow, a phase can be defined as an identifiable class of material that has a particular inertial response to and interaction with the flow and the potential field in which it is immersed. There are two approaches for the numerical calculation of multiphase flows: the Euler-Lagrange approach and the Euler-Euler approach.

\subsection{Euler-Lagrange Approach}

Discrete Phase Model (DPM): The fluid phase is treated as a continuum by solving the time-averaged Navier-Stokes equations, while the dispersed phase is solved by tracking a large number of particles, bubbles, or droplets through the calculated flow field. The dispersed phase can exchange momentum, mass, and energy with the fluid phase. A fundamental assumption made in this model is that the dispersed second phase occupies a low volume fraction. The particle or droplet trajectories are computed individually at specified intervals during the fluid phase calculation. This makes the model appropriate for any application where the volume fraction of the second phase is not negligible.

\subsection{Euler-Euler Approach}


In the Euler-Euler approach, the different phases are treated mathematically as interpenetrating continua. Since the volume of a phase cannot be occupied by the other phases, the concept of phasic volume fraction is introduced. These volume fractions are assumed to be continuous functions of space and time and their sum is equal to one. Conservation equations for each phase are derived to obtain a set of equations, which have similar structure for all phases. These equations are closed by providing constitutive relations that are obtained from empirical information, and in the case of granular flows, by application of kinetic theory. Three different Euler-Euler multiphase models are available: the volume of fluid (VOF) model, the mixture model, and the Eulerian model.

VOF model: This is a surface-tracking technique applied to a fixed Eulerian mesh. It is designed for two or more immiscible fluids where the position of the interface between the fluids is of interest. In the VOF model, a single set of momentum equations is shared by the fluids, and the volume fraction of each of the fluids in each computational cell is tracked throughout the domain.

Mixture Model: The mixture model is designed for two or more phases (fluid or particulate). As in the Eulerian model, the phases are treated as interpenetrating continua. The mixture model solves for the mixture momentum equation and prescribes relative velocities to describe the dispersed phases. The mixture model can also be used without relative velocities for the dispersed phases to model homogeneous multiphase flow. 
Eulerian Model: The Eulerian model is the most complex of the multiphase models in Fluent. It solves a set of momentum and continuity equations for each phase. Coupling is achieved through the pressure and interphase exchange coefficients. The manner in which this coupling is handled depends upon the type of phases involved; granular (fluid-solid) flows are handled differently than non-granular (fluid-fluid) flows. For granular flows, the properties are obtained from application of kinetic theory. Momentum exchange between the phases is also dependent upon the type of mixture being modeled. With the Eulerian multiphase model, the number of secondary phases is limited only by memory requirements and convergence behavior. Any number of secondary phases can be modeled, provided that sufficient memory is available. For complex multiphase flows, however, one may find that the solution is limited by convergence behavior.

\subsubsection{Material Types and Properties}

Physical model may require the inclusion of additional material properties. Material properties are defined in the Fluent Panel. The material type (cuttings), density and viscosity need to be defined for each of the phases. Also the operating conditions, like gravity and operating pressure need to be inputed into the model.

\subsubsection{Boundary Conditions}

The boundary conditions specify the flow and the thermal variables on the boundaries of the physical model. They are a critical component of the Fluent simulations. Fluent has wide range of boundary conditions that permit flow to enter and exit the solution domain. The inlet and exit boundary condition options in Fluent are as follows: 
- Velocity inlet boundary conditions are used to define the velocity and scalar properties of the flow at inlet boundaries.

- Pressure inlet boundary conditions are used to define the total pressure and other scalar quantities at flow inlets.

- Mass flow inlet boundary conditions are used in compressible flows to prescribe a mass flow rate at an inlet. It is not necessary to use mass flow inlets in incompressible flows because when density is constant, velocity inlet boundary conditions will fix the mass flow.

- Pressure outlet boundary conditions are used to define the static pressure at flow outlets (and also other scalar variables, in case of backflow). The use of a pressure outlet boundary condition instead of an outflow condition often results in a better rate of convergence when backflow occurs during iteration.

- Pressure far-field boundary conditions are used to model a free-stream compressible flow at infinity, with free-stream Mach number and static conditions specified. This boundary type is available only for compressible flows.

- Outflow boundary conditions are used to model flow exits where the details of the flow velocity and pressure are not known prior to solution of the flow problem. They are appropriate where the exit flow is close to a fully developed condition, as the outflow boundary condition assumes a zero normal gradient for all flow variables except pressure. They are not appropriate for compressible flow calculations. 
- Inlet vent boundary conditions are used to model an inlet vent with a specified loss coefficient, flow direction, and ambient (inlet) total pressure and temperature.

- Intake fan boundary conditions are used to model an external intake fan with a specified pressure jump, flow direction, and ambient (intake) total pressure and temperature.

- Outlet vent boundary conditions are used to model an outlet vent with a specified loss coefficient and ambient (discharge) static pressure and temperature.

- Exhaust fan boundary conditions are used to model an external exhaust fan with a specified pressure jump and ambient (discharge) static pressure.

\section{CHAPTER 3}

\section{MODEL SETUP}

The mesh for the flow system was created in Gambit and was imported into Fluent. We used the three-dimensional double precision (3ddp) fluent solver as it is more accurate. The segregated solution method is the solution algorithm used in this study. The coupled solver requires a larger amount of memory and computational time; hence we chose the segregated solver. Plus, segregated solver provides flexibility in solution procedure. In the segregated solution method there is a system of linear equations with one equation for each cell in the domain. Because there is only one equation per cell, this is sometimes called a scalar system of equations. A point implicit (Gauss-Seidel) linear equation solver is used in conjunction with an algebraic multigrid method to solve the resultant scalar system of equations for the dependent variable in each cell. For example, the momentum 
equation is linearized to produce a system of equations in which velocity is the unknown. Simultaneous solution of this equation system yields an updated velocity field. The segregated approach solves for a single variable field by considering all cells at the same time. It then solves for the next variable field by again considering all cells at the same time, and so on. The approach used is an implicit one.

For high loading, there is a two-way coupling plus particle pressure and viscous stresses due to particles (four-way coupling). Only the Eulerian multiphase model will handle this type of problem correctly. The particles will move independently of the flow and in this case, the Eulerian model is applicable. To change from a single-phase model, where a single set of conservation equations for momentum, continuity and (optionally) energy is solved, to a multiphase model, additional sets of conservation equations must be introduced. In the process of introducing additional sets of conservation equations, the original set must also be modified. The modifications involve, among other things, the introduction of the volume fractions for the multiple phases, as well as mechanisms for the exchange of momentum, heat, and mass between the phases. The equations and the algorithm for the Eulerian Model are described in detail in APPENDIX A.

The boundary conditions available for the Eulerian multiphase model simulations are limited. In our case, the velocity inlet boundary conditions are used to define the velocity and scalar properties of the flow at the inlet boundaries. The following inputs are necessary at the velocity inlet boundary conditions:

- Velocity magnitude and direction or velocity components 
- Turbulence parameters

- Multiphase boundary conditions (In our case volume fractions of secondary phase and its velocity)

The turbulence parameters used depend on the turbulence model used. For multiphase transport, we used the k- $\varepsilon$ multiphase model. For the turbulence parameters, specification of a uniform value of the turbulence quantity is done. This is done in the case where the profiles of velocity are not available. In our case, the turbulence quantities used are hydraulic diameter and turbulence intensity.

$$
D_{h}=(D-d)
$$

Turbulence Intensity $(\mathrm{T} . \mathrm{I})=0.16 \times\left(\mathrm{Re}_{D_{\mathrm{h}}}\right)^{-\frac{1}{8}}$

For our outlet, we use the pressure outlet boundary conditions. The following information is entered at the pressure outlet boundary conditions.

- $\quad$ Static Pressure

- Backflow conditions

Wall boundary conditions are used to bound fluid and solid regions. In viscous flow, the no-slip boundary condition is enforced at the walls. But, while modeling pipe rotation, we specify the angular rotational speed of the internal wall. Our procedure for the simulations is outlined in Figure 8. 


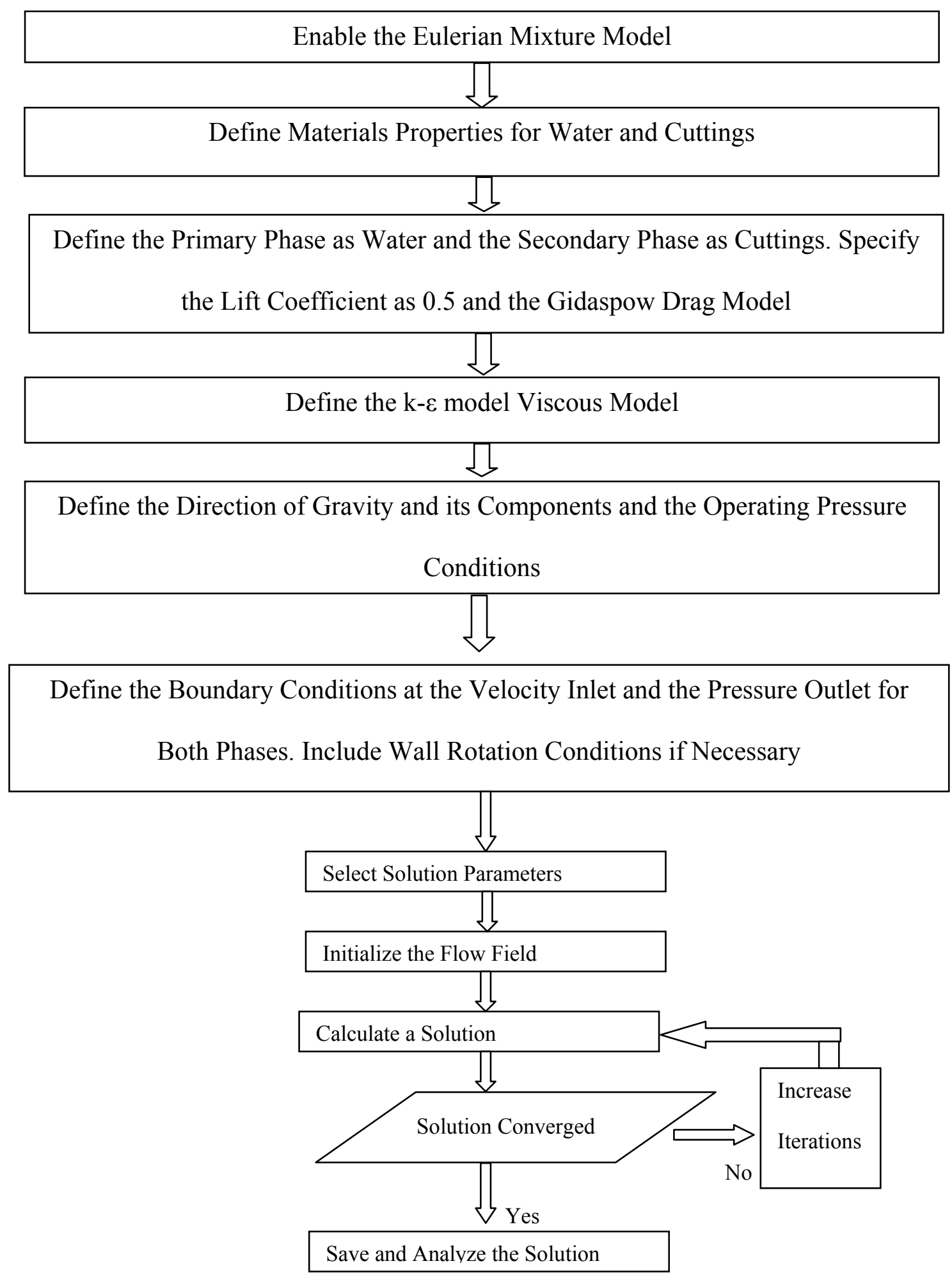

Figure 8: Eulerian simulation procedure in Fluent. 


\subsection{Model Domain}

Throughout this study a 45 foot annular section of two concentric pipes was used. The outer casing/hole diameter was 6.0 inch and the drill pipe diameter was 3.5 inch. The creation of this section was done in the Fluent preprocessor-Gambit. This length was chosen keeping the computational time in mind. A larger annular section would contain numerous cells making the computational time much longer and convergence criteria much harder. Drill pipe rotation is also considered in this study. The drill pipe rotation is facilitated by providing angular velocity to the inner wall (drill pipe) in the annular section. Since the geometry is not complex, uniform hexahedron cells are created using the Cooper's Meshing (Volume) Scheme. The resulting cell size is shown in Figure 9. The entire grid in four different views is shown in Figure 10. The only constraint with the cell size is that the smallest to the largest side ratio should be greater than 0.2. This condition holds true in this case.

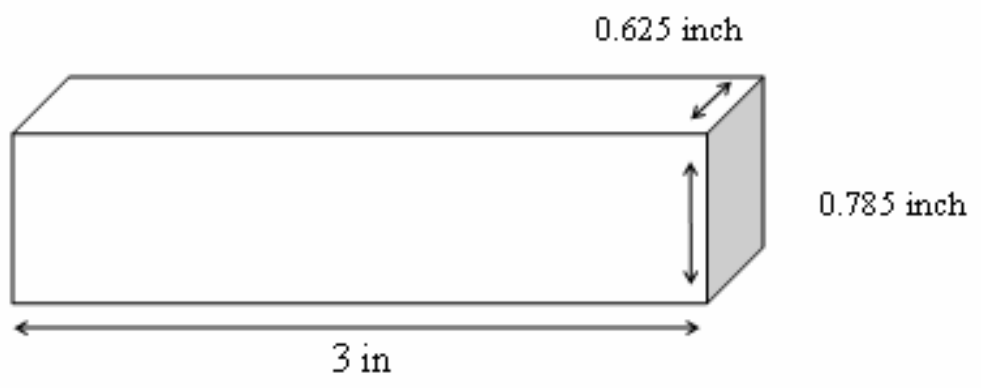

Figure 9: Grid size of each cell in the annular section. 


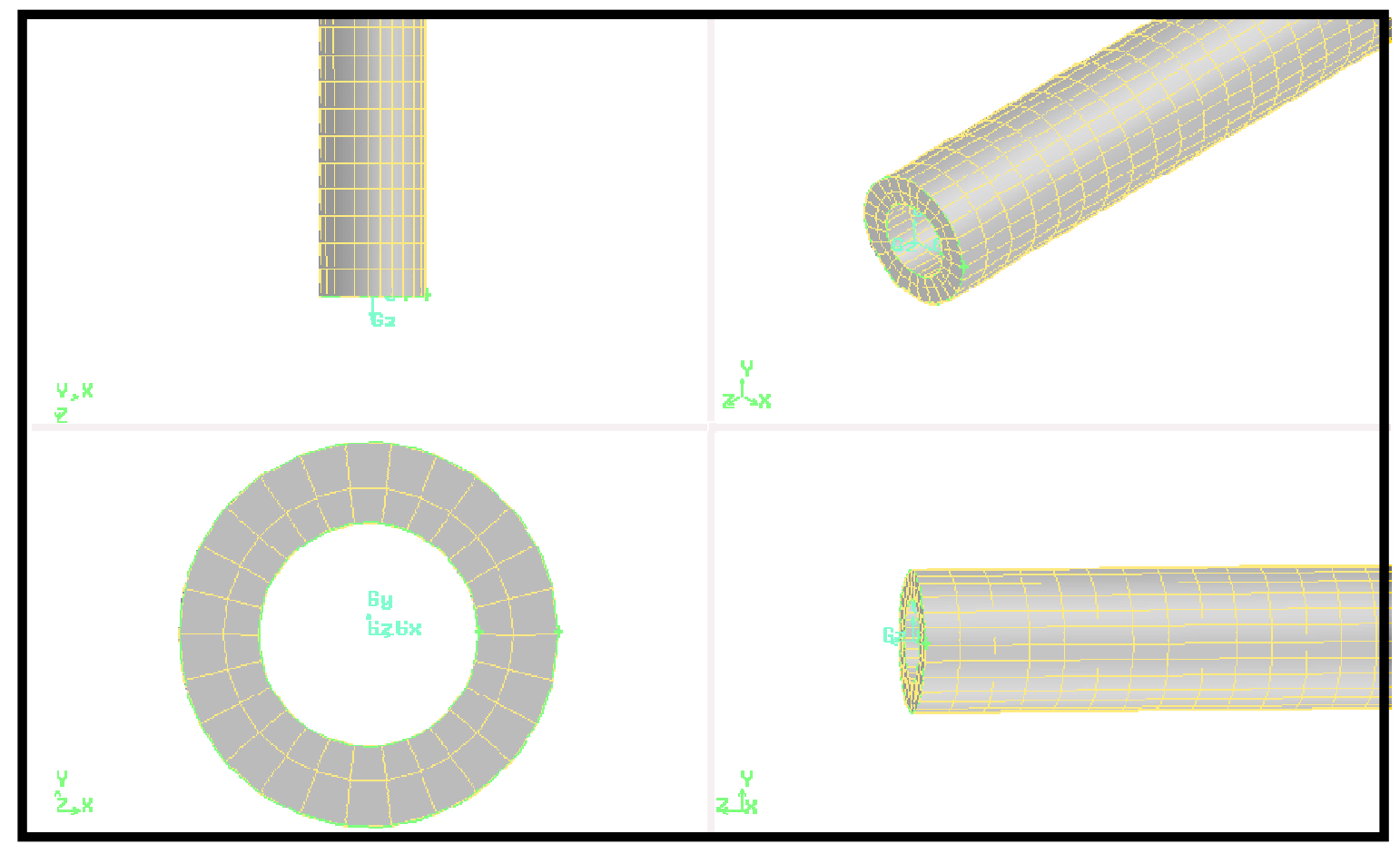

Figure 10: Domain created by Gambit.

The operating pressure used was 200 psia for all the simulations. The boundary types chosen were velocity inlet and pressure outlet. The turbulence parameters were calculated according to the fluid flow rate. The fluid used in this study was water. Although water is not used generally as a cleaning fluid, it was chosen as computational expense would be minimal (it is an incompressible newtonian fluid). Also mud is not used because there is no data to verify the validity of a non-newtonian model in CFD. The particles used were assumed to have a density of $2610 \mathrm{~kg} / \mathrm{m}^{3}$ (specific gravity of 2.61 ). The domain created consisted of 9360 hexahedral cells. 


\subsection{Parameters Studied}

\subsubsection{Flow Rate}

Throughout this study all the simulations were done using three different flow rates. These flow rates were changed by changing the primary phase's (water) inlet velocity at the inflow boundary. The three different flow rates were $100 \mathrm{gal} / \mathrm{min}, 120 \mathrm{gal} / \mathrm{min}$ and $150 \mathrm{gal} / \mathrm{min}$. The input velocities are shown in Table 2 and the formula for the relationship between the flow rate and the inlet velocity is given as:

\begin{tabular}{|c|c|c|}
\hline \multirow[t]{5}{*}{ Input Velocity = } & $\frac{\text { Flow Rate }}{\text { Area of the Annulus }}$ & \\
\hline & Flow Rate in Annulus(gal/min) & Velocity in Annulus(ft/min) \\
\hline & 120 & 123.83 \\
\hline & 150 & 154.79 \\
\hline & 180 & 185.75 \\
\hline
\end{tabular}

Table 2: Input values of velocity of water in the annulus.

The turbulence parameters at the inlet were calculated according to the velocity of the primary phase (water) at the inlet. These range of flow rate values were selected based on the general norms followed in the industry.

\subsubsection{Cutting Size}

To study the effect of cutting size, two different particle sizes are studied. The choice of size was based on an effort to study the impact of two different classes of particle sizes. The two different sizes of particles studied were the $3 \mathrm{~mm}(0.118 \mathrm{inch})$ and $8 \mathrm{~mm}(0.3716$ inch) particles. The $3 \mathrm{~mm}$ particles are classified as small particles and the $8 \mathrm{~mm}$ particles 
are classified as medium sized particles. These values were directly used in defining the particle size in CFD.

\subsubsection{Rate of Penetration (ROP)}

In this study, the effect of rate of penetration is assessed. Three different ROP values are used, namely $50 \mathrm{ft} / \mathrm{hr}, 100 \mathrm{ft} / \mathrm{hr}$ and $150 \mathrm{ft} / \mathrm{hr}$. As part of the Eulerian boundary conditions in CFD, we need to input the volume fraction and the velocity of the cuttings (phase-2) at the velocity inlet boundary. A fix input volume fraction of $4 \%$ is used for cuttings volumetric concentration and the velocity values were calculated by a simple mass balance. The rock is assumed to have a uniform porosity of $38 \%$. The velocity values used for the secondary phase are calculated with the following equation and the results are shown in Table 3.

$$
V_{\text {cut }}=\frac{R O P \times A_{\text {hole }} \times(1-\text { porosity })}{C_{\text {conc }} \times A_{\text {annulus }}}
$$

\begin{tabular}{|c|c|}
\hline $\begin{array}{c}\text { ROP } \\
\text { (ft/hr) }\end{array}$ & $\begin{array}{c}\text { Cuttings Velocity } \\
\text { (ft/min) }\end{array}$ \\
\hline 50 & 19.57 \\
\hline 75 & 29.37 \\
\hline 100 & 39.15 \\
\hline
\end{tabular}

Table 3: Input velocity of phase-2 (cuttings) at $4 \%$ volume fraction. 


\subsubsection{Drill pipe Rotation}

In CFD, drillpipe rotation is achieved by providing an angular velocity value to the inner wall. Three different drillpipe rotation values of $0 \mathrm{rpm}, 30 \mathrm{rpm}$ and $60 \mathrm{rpm}$ were used in this study.

\subsubsection{Angle of Inclination}

Three different values of angle of inclination are studied. These angles are the harder to clean angles as stated by Tormen et. al. ${ }^{[4]}$
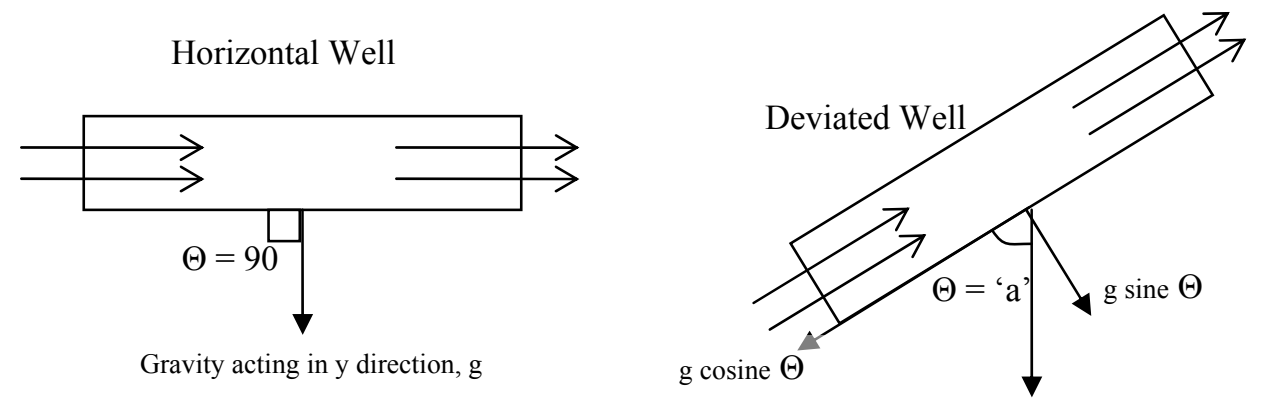

Figure 11: Forces acting due to deviation in the well.

The horizontal well, as seen in Figure 11 are assumed to be at 90 degrees. The two other angles of deviation studied are at 75 degrees and 60 degrees. The values of the components of gravity have to be feed into the operating conditions panel in Fluent. The calculations for the components are shown in the figure above and the values given in Table 4. 


\begin{tabular}{|c|c|c|}
\hline $\begin{array}{c}\text { Angle } \\
\text { (degrees) }\end{array}$ & $\begin{array}{c}\text { Gravity ' } \mathrm{y} \text { ' } \\
\text { Component } \\
\left(\mathrm{m} / \mathrm{s}^{2}\right)\end{array}$ & $\begin{array}{c}\text { Gravity ' } \mathrm{z} \text { ' } \\
\text { Component } \\
\left(\mathrm{m} / \mathrm{s}^{2}\right)\end{array}$ \\
\hline 90 & -9.81 & 0.00 \\
\hline 75 & -9.46 & -2.54 \\
\hline 60 & -8.49 & -4.90 \\
\hline
\end{tabular}

Table 4: Input values for gravity effects in deviated well.

The parameters studied are summarized in Table 5 .

\begin{tabular}{|c|c|c|}
\hline Property & Unit & V alues \\
\hline \multirow{2}{*}{ Flow Rates } & $\mathrm{gpm}$ & $120,150,180$ \\
\cline { 2 - 3 } & $\mathrm{ft}^{3} / \mathrm{min}$ & $16.04,20.05,24.06$ \\
\hline \multirow{2}{*}{ Cutting Sizes } & $\mathrm{mm}$ & 3,8 \\
\cline { 2 - 3 } & inch & $0.118,0.372$ \\
\hline \multirow{2}{*}{ Rate of Penetration(ROP) } & $\mathrm{fthr}$ & $50,75,100$ \\
\cline { 2 - 3 } & $\mathrm{m} / \mathrm{hr}$ & $15.24,22.86,30.48$ \\
\hline Drill Pipe Rotation & rpm & $0,30,60$ \\
\hline Angle of Inclination & degrees & $90,75,60$ \\
\hline
\end{tabular}

Table 5: Summary of parameters studied. 


\subsection{Model Verification}

Before conducting simulations using the Eulerian Model in CFD, the simulations were checked against the experimental work of Zhou ${ }^{[21]}$. Zhou ${ }^{[21]}$ examined the hole cleaning parameters using aerated flow at elevated temperature and elevated pressure. Although he conducted bulk of his experiments using air, water and cuttings, there were some experiments in which only water was used as the hole cleaning fluid. His experiments were conducted on a 75-foot long annular section with a 6 inch inner diameter casing and a 3.5 inch drillpipe. The average size of the injected cuttings were 0.118 inch $(3 \mathrm{~mm})$. They were injected at a constant rate of $6.8 \mathrm{~kg} / \mathrm{min}$ corresponding to a ROP of $50 \mathrm{ft} / \mathrm{hr}$. The flow loop was first filled with water and then the cuttings were injected. After steady state conditions were reached, i.e. the cuttings injection rate was the same as the removal rate, the experiments were stopped and the concentration of the cuttings in the annulus was measured. The pressure drop across the annulus and cutting concentrations obtained by $\mathrm{Zhou}^{[21]}$ are summarized in Table 6 .

\begin{tabular}{|c|c|c|}
\hline Flow Rate (gpm) & Total Pressure Drop (psi) & Cutting Concentrations (\%) \\
\hline 80 & 1.310 & 35.01 \\
\hline 120 & 1.362 & 19.63 \\
\hline 150 & 1.209 & 10.16 \\
\hline
\end{tabular}

Table 6: Zhou $^{[21]}$ experimental results. 
To check the validity of the Eulerian model, unsteady state simulations were used in our study. Initially, the pipe was assumed to be filled with water and then the cuttings were injected with the same mass flow rate as the experiments. At $4 \%$ volumetric concentration, the velocity of the cuttings were calculated as $19.57 \mathrm{ft} / \mathrm{min}$. The simulations were carried out at individual flow rates for about 200,000 iterations. Steady state conditions had not been achieved but the value of cutting concentration in the annulus were averaged out and compared. Contours of pressure and phase volume fraction were drawn out and compared with the experimental studies. The pressure drop per foot comparisons are shown in Figure 12 and the cutting concentrations comparisons are shown in Figure 13. The pressure drops per foot in the simulated results are almost equal to the experimental results. The cutting concentrations in the annulus were comparable but there was a significant difference at a lower flow rate of $80 \mathrm{gpm}$. Stratified flow was observed throughout the annular section and the formation of cutting bed was observed close to the velocity inlet of annular section. The general differences were not too large and hence we could conclude that the Eulerian model in CFD could be used to conduct our parametric study. 


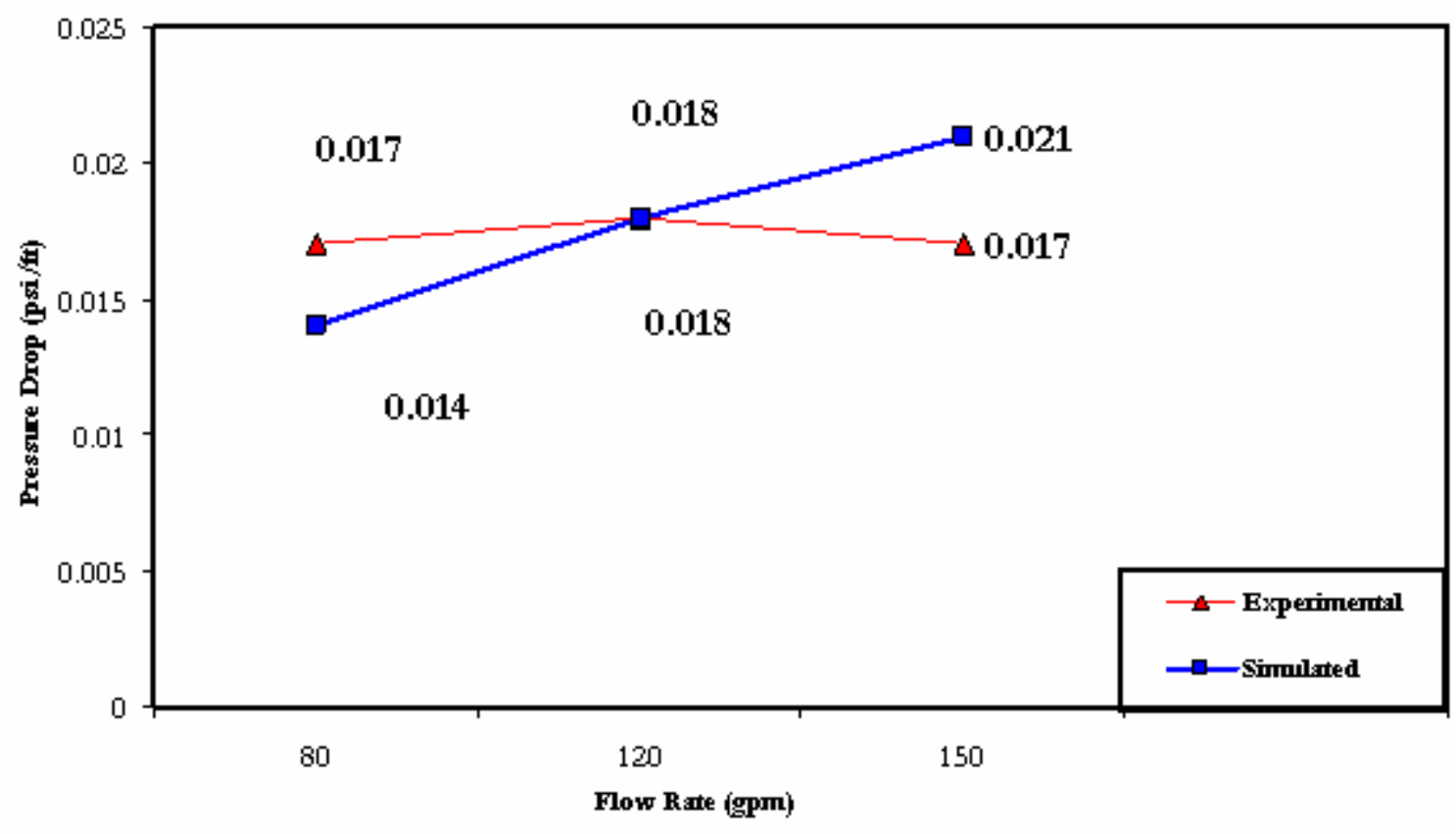

Figure 12: Comparison of model predicted pressure drop values across annulus with lab data.

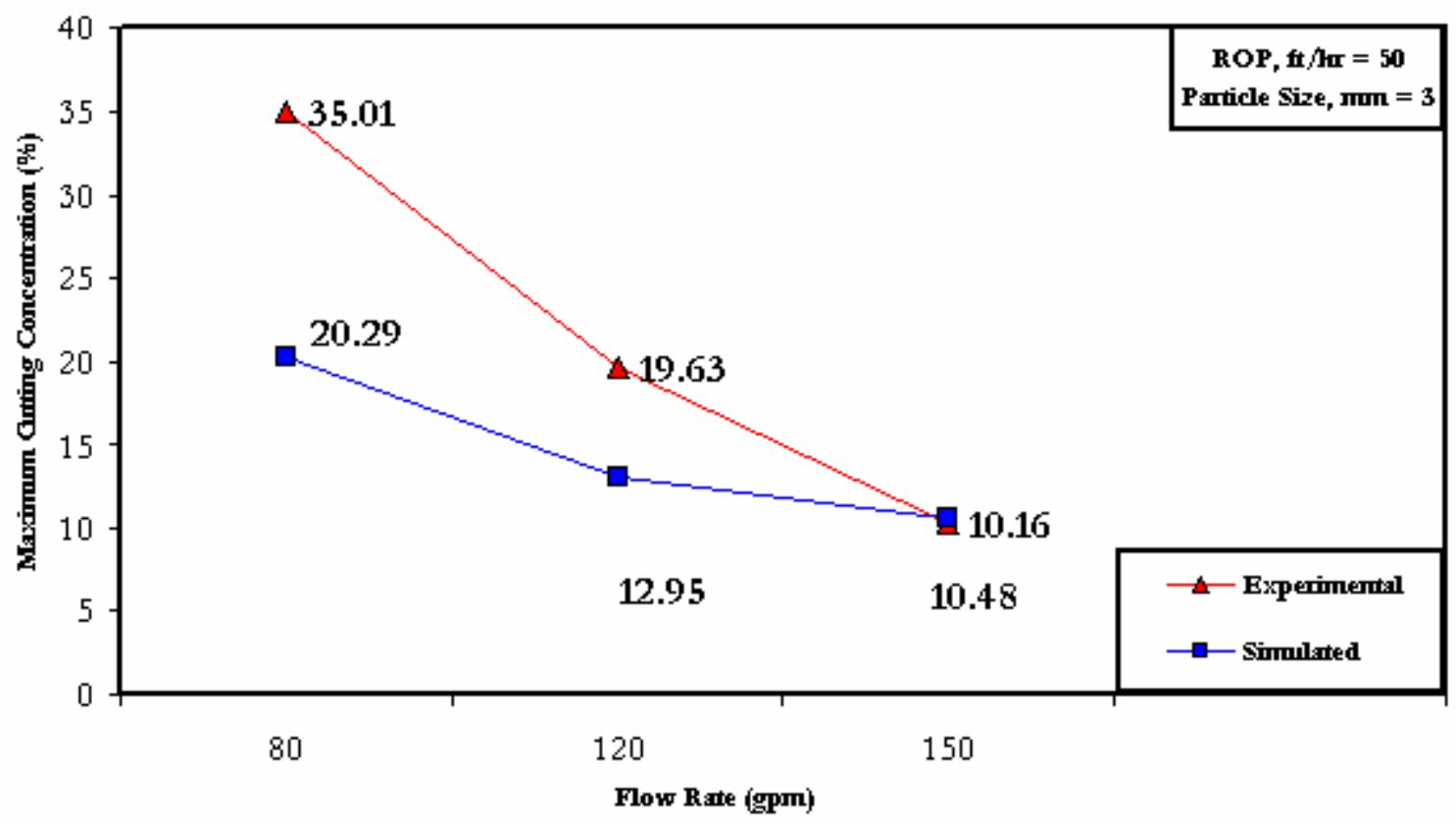

Figure 13: Comparison of cutting concentrations from model prediction with lab data. 


\section{CHAPTER 4}

\section{RESULTS AND DISCUSSION}

In this chapter, the results of the hole cleaning parametric analysis using CFD are summarized. Runs were conducted at steady state and in some cases it took approximately 70,000 iterations to converge. A total of three flow rates, two particles sizes, three rates of penetration (ROP), three drillpipe rotation speeds, and three hole angles were considered in this study. The results are discussed first in this section and then analyzed for each of the parameters studied. The Newtonian fluid used in this modeling study was water and all the flow rates of 120, 150 and 180 gpm investigated for horizontal wells lie within the turbulence region. In horizontal pipes, the effect of flow rate and rate of penetration are shown in Figure 14 through Figure 19 for cutting sizes 3 $\mathrm{mm}$ and $8 \mathrm{~mm}$ with rotating and non rotating drill pipe conditions.

Without drillpipe rotation, for $3 \mathrm{~mm}$ particle sizes (Figure 14), at a $50 \mathrm{ft} / \mathrm{hr} \mathrm{ROP}$, the cuttings concentration drops from $12.9 \%$ to $10.5 \%$ when the flow rate increases from $120 \mathrm{gpm}$ to $150 \mathrm{gpm}$. The cutting concentration further drops to $9.6 \%$ when the flow rate is increased to $180 \mathrm{gpm}$. When the ROP is increased to $75 \mathrm{ft} / \mathrm{hr}$, the cutting concentration values observed were $15.4 \%, 12.2 \%$ and $11.9 \%$ for $120 \mathrm{gpm}, 150 \mathrm{gpm}$, and $180 \mathrm{gpm}$, respectively. At the $100 \mathrm{ft} / \mathrm{hr}$ ROP, when the circulation rate was $120 \mathrm{gpm}$ the cutting concentration was $19.4 \%$, gradually dropping to $17.5 \%$ and then to $16 \%$ as the flow rates increased to 150 and then 180 gpm, respectively. 


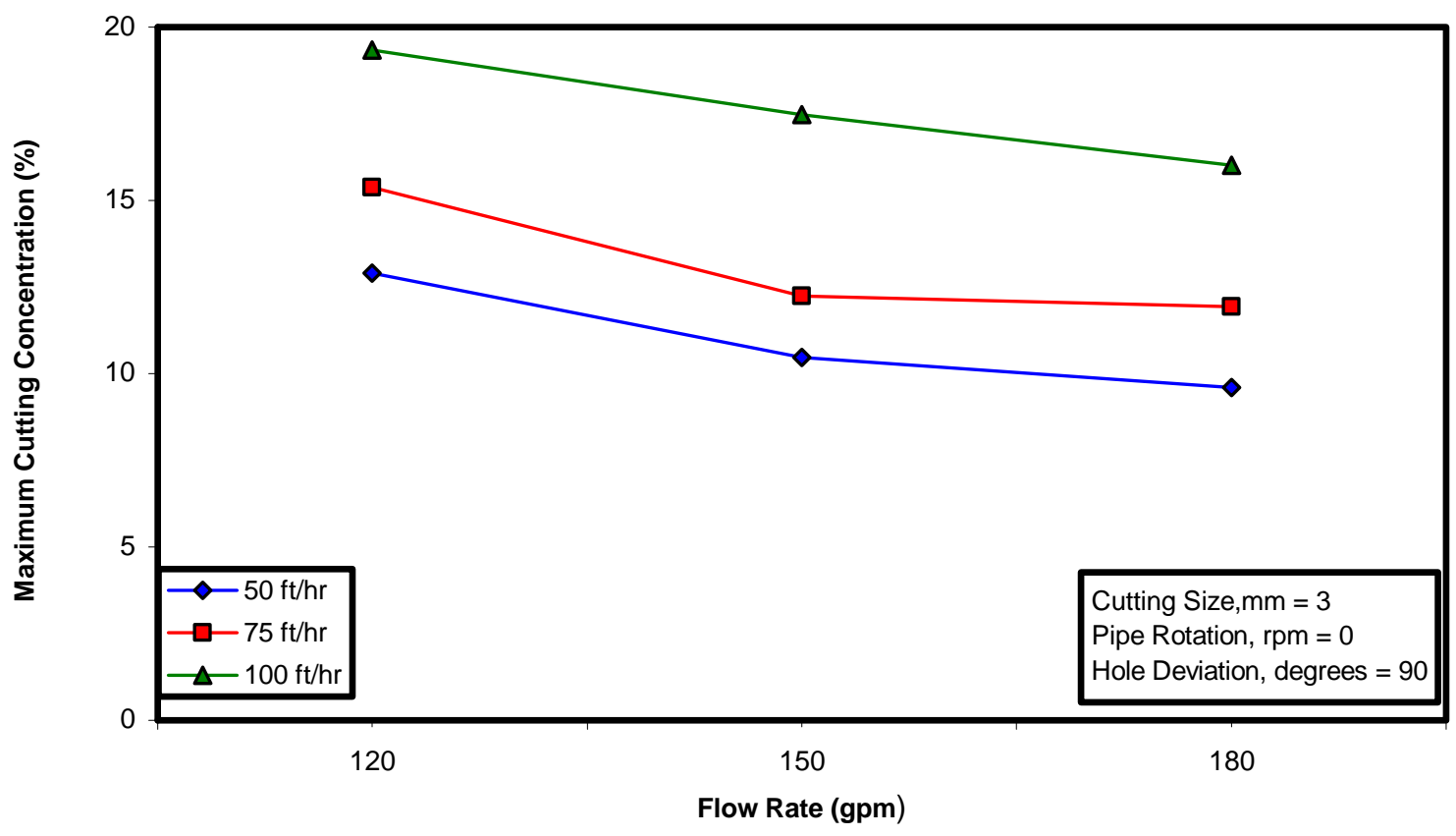

Figure 14: Variation of cutting concentration with flow rate for $3 \mathrm{~mm}$ particles.

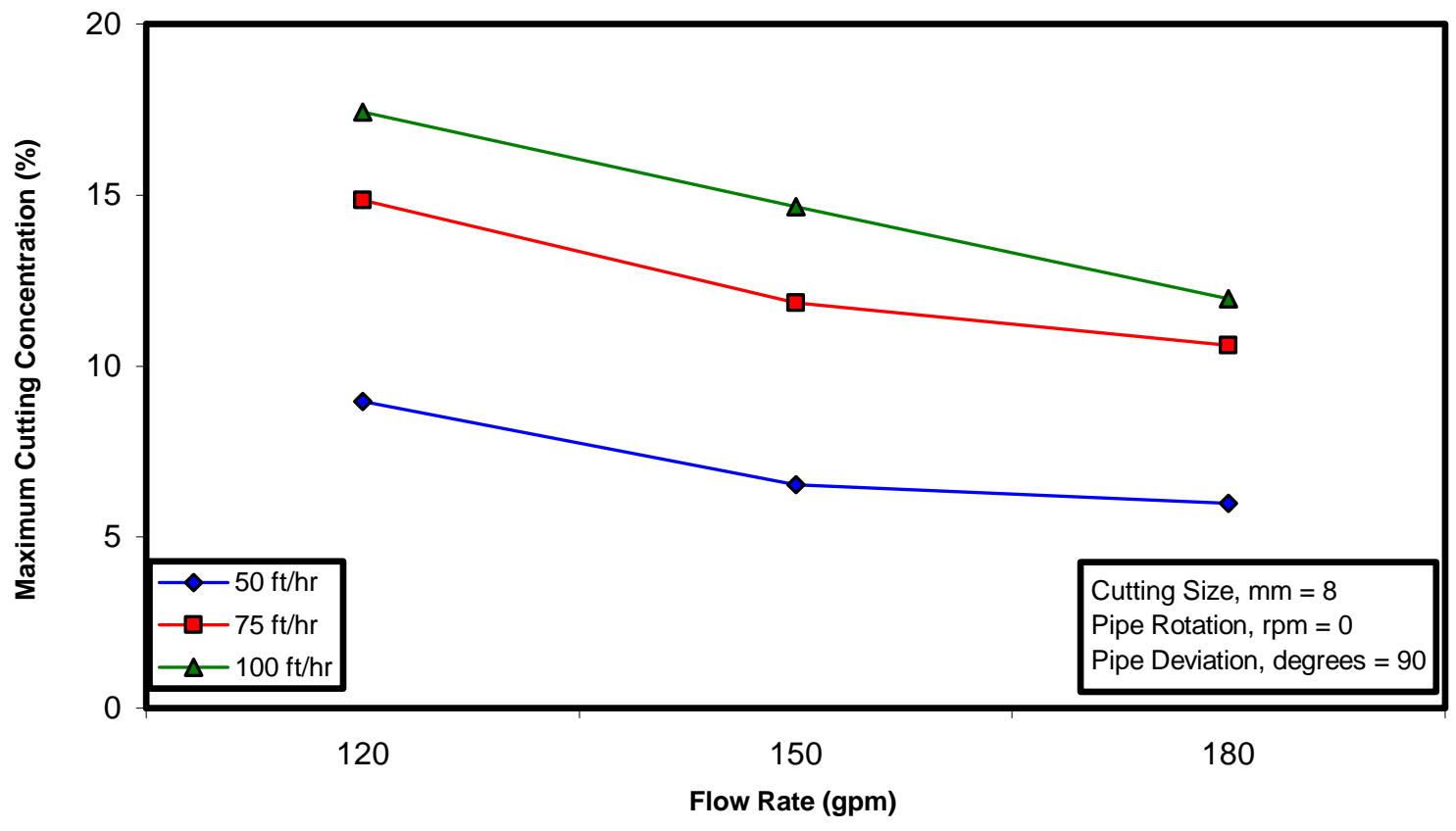

Figure 15: Variation of cutting concentration with flow rate for $8 \mathrm{~mm}$ particles. 
Figure 15 shows the results for $8 \mathrm{~mm}$ particles in the horizontal section, where the inner pipe rotation is zero. At $50 \mathrm{ft} / \mathrm{hr} \mathrm{ROP}$, the cutting concentration in the annulus section dropped from $8.8 \%$ to $6.0 \%$ as the flow rate increased from $120 \mathrm{gpm}$ to $180 \mathrm{gpm}$. At 75 $\mathrm{ft} / \mathrm{hr}$ ROP, the cutting concentration is reduced from $14.8 \%$ to $11.8 \%$ and then to $10.6 \%$ as the flow rate is increased from $120 \mathrm{gpm}$ to $150 \mathrm{gpm}$ and then to $180 \mathrm{gpm}$. Similarly, for a drilling rate of $100 \mathrm{ft} / \mathrm{hr}$, the cutting concentration is reduced from $17.5 \%$ to $14.6 \%$ as the flow rate is increased from $120 \mathrm{gpm}$ to $150 \mathrm{gpm}$. The cutting concentration is further reduced to $11.9 \%$ as the flow rate is increased to $180 \mathrm{gpm}$. The tendency as seen in both figures is that the flow rate helps to reduce the cuttings concentration in the annulus in horizontal wells for both particles sizes at all ROP values.

To examine closely the effect of flow rate in reduction of cuttings in the annulus, the 'concentration change percentages' over the range of flow rates studied were calculated for the $3 \mathrm{~mm}$ and $8 \mathrm{~mm}$ particles at their respective ROP values using Equation 5. The concentration change percentages for $3 \mathrm{~mm}$ and $8 \mathrm{~mm}$ particles without drill pipe rotation are shown in Table 7.

Conc. Change $(\%)=\frac{\text { Cutting Conc. at } 120 \text { gpm }- \text { Cutting Conc. at } 180 \mathrm{gpm}}{\text { Cutting Conc. at } 120 \text { gpm }} \times 100 \ldots \ldots$ (5) 


\begin{tabular}{|c|c|c|c|}
\hline \multirow{2}{*}{ Cutting Sizes } & \multicolumn{3}{|c|}{ ROP } \\
\cline { 2 - 4 } & $50 \mathrm{ft} / \mathrm{hr}$ & $75 \mathrm{ft} / \mathrm{hr}$ & $100 \mathrm{ft} / \mathrm{hr}$ \\
\hline $3 \mathrm{~mm}$ & $25.7 \%$ & $22.4 \%$ & $19.3 \%$ \\
\hline $8 \mathrm{~mm}$ & $36.4 \%$ & $32.5 \%$ & $33.7 \%$ \\
\hline
\end{tabular}

Table 7: Concentration change percentages for particles in horizontal wells without drillpipe rotation.

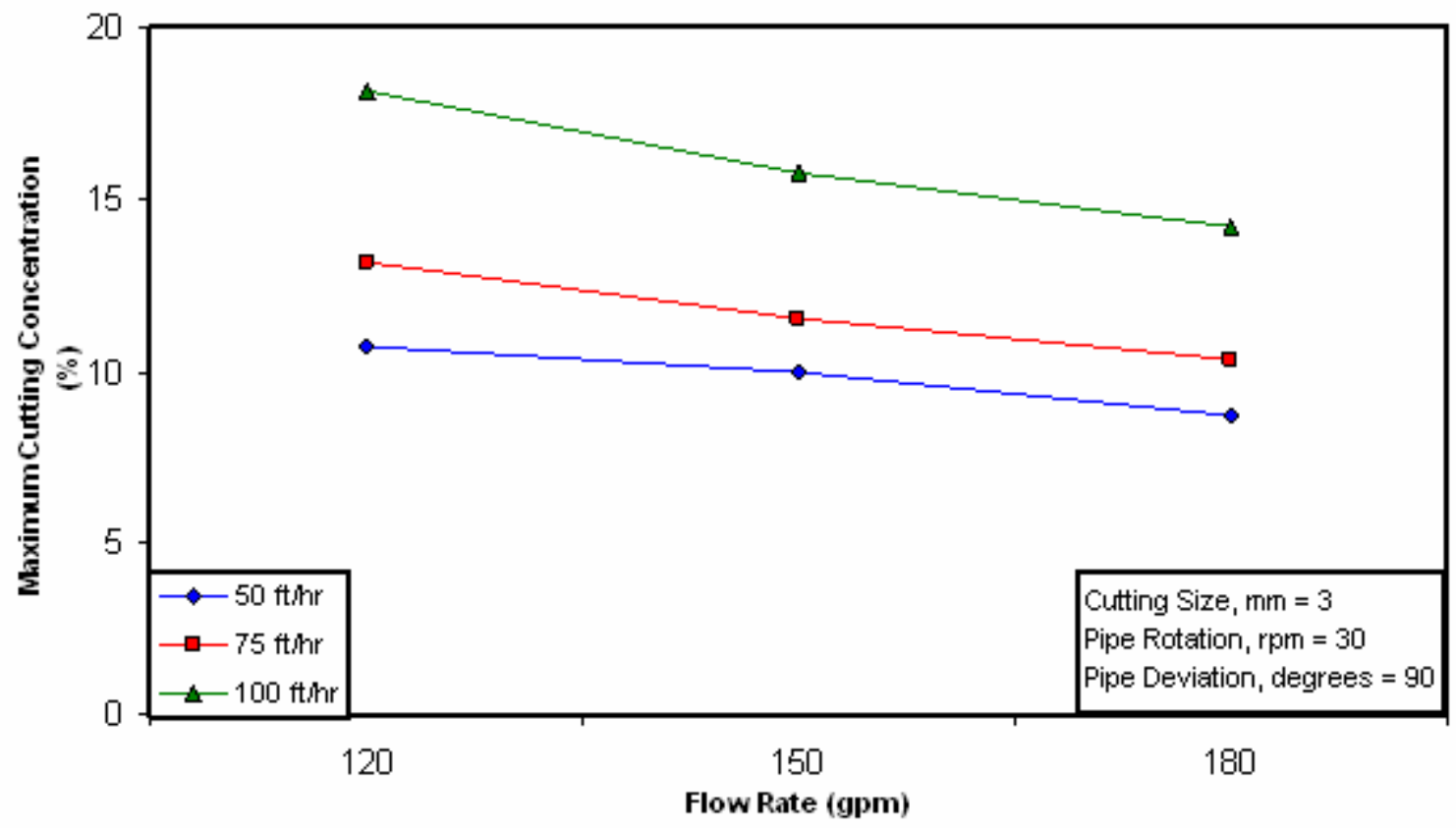

Figure 16: Variation of cutting concentration with flow rate for $3 \mathrm{~mm}$ particles.

Figure 16 shows the results for $3 \mathrm{~mm}$ particles in the horizontal section. When the inner pipe is rotated at $30 \mathrm{rpm}$, the cutting concentration dropped from $10.7 \%$ to $8.7 \%$ with the increase in circulation rate from $120 \mathrm{gpm}$ to $180 \mathrm{gpm}$ for a $50 \mathrm{ft} / \mathrm{hr}$ ROP. For the drill rate of $75 \mathrm{ft} / \mathrm{hr}$ the cutting concentration declined from $13.1 \%$ to $10.3 \%$ when the flow rate is increased from $120 \mathrm{gpm}$ to $180 \mathrm{gpm}$. At the highest ROP value used in this study 
(100 ft/hr), the cutting concentration lowered from $18.2 \%$ to $14.2 \%$ as the flow rate is increased from $120 \mathrm{gpm}$ to $180 \mathrm{gpm}$. For a horizontal well, the values for 'concentration change percentages' (calculated with Equation 5) for $3 \mathrm{~mm}$ particles under $30 \mathrm{rpm}$ inner pipe rotation are shown in Table 8 .

\begin{tabular}{|c|c|c|c|}
\hline \multirow{2}{*}{ Cutting Sizes } & \multicolumn{3}{|c|}{ ROP } \\
\cline { 2 - 4 } & $50 \mathrm{ft} / \mathrm{hr}$ & $75 \mathrm{ft} / \mathrm{hr}$ & $100 \mathrm{ft} / \mathrm{hr}$ \\
\hline $3 \mathrm{~mm}$ & $19.2 \%$ & $21.4 \%$ & $21.8 \%$ \\
\hline
\end{tabular}

Table 8: Concentration change percentages for $3 \mathrm{~mm}$ particles in horizontal wells with drillpipe rotation.

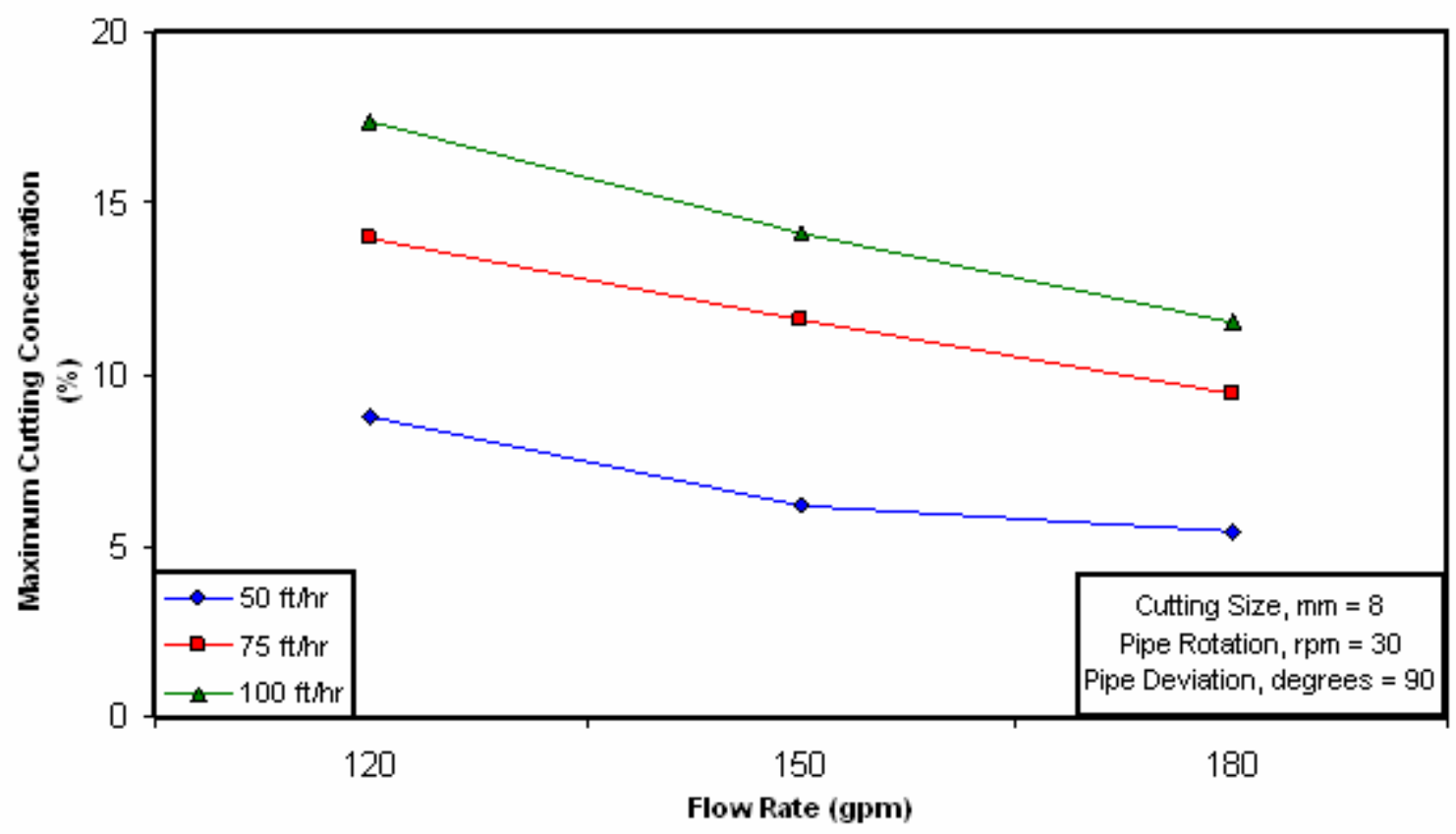

Figure 17: Variation of cutting concentration with flow rate for $8 \mathrm{~mm}$ Particles.

The results are shown in Figure 17 for $8 \mathrm{~mm}$ sized particles with $30 \mathrm{rpm}$ drill pipe rotation in a horizontal well. For the footage value of $50 \mathrm{ft} / \mathrm{hr}$, the cutting concentrations 
values observed were $8.7 \%, 6.1 \%$ and $5.4 \%$ for $120 \mathrm{gpm}, 150 \mathrm{gpm}$ and $180 \mathrm{gpm}$, respectively. For the drill rate of $75 \mathrm{ft} / \mathrm{hr}$ the cutting concentration reduced from $14 \%$ to $11.6 \%$ when the flow rate is increased from $120 \mathrm{gpm}$ to $180 \mathrm{gpm}$. At the highest ROP value used in this study $(100 \mathrm{ft} / \mathrm{hr})$, the cutting concentration dropped from $17.4 \%$ to $11.5 \%$ as the flow rate is increased from $120 \mathrm{gpm}$ to $180 \mathrm{gpm}$. The average 'concentration change percentages' (a closer look at the effect of flow rate on cutting concentration in the annulus) were approximately $33 \%$ for all the ROP values studied.

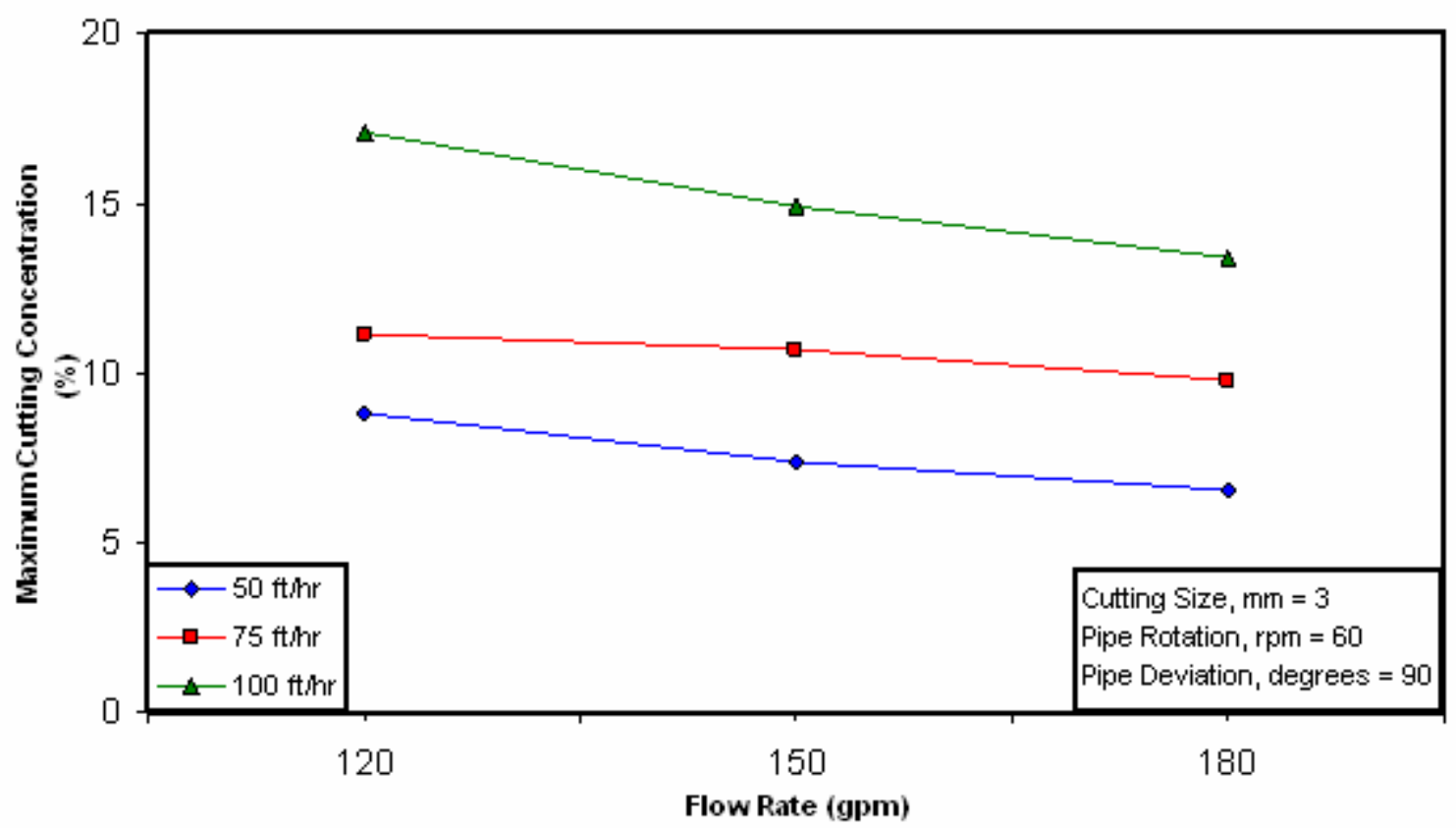

Figure 18: Variation of cutting concentration with flow rate for $3 \mathrm{~mm}$ Particles. 


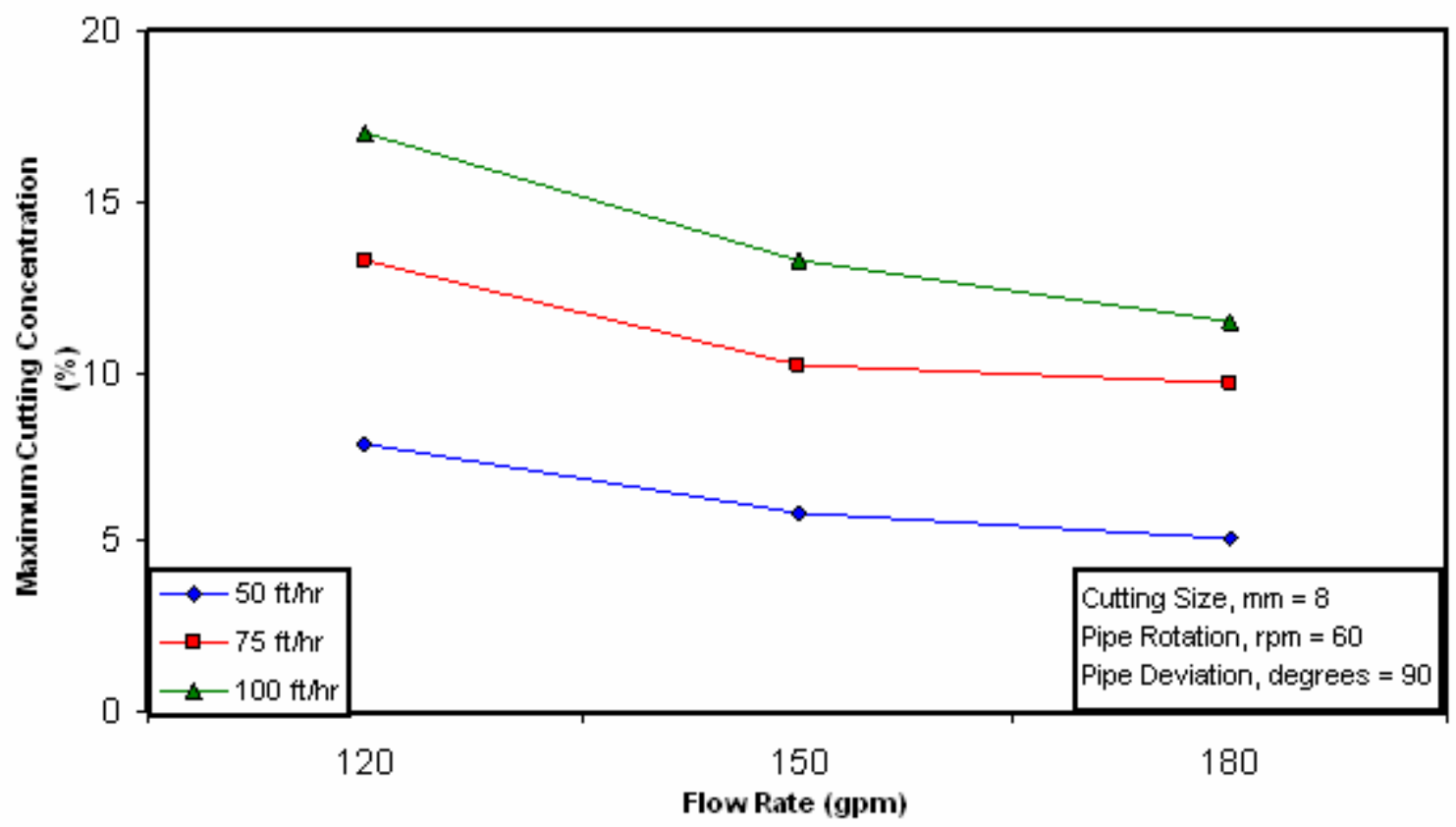

Figure 19: Variation of cutting concentration with. flow rate for $3 \mathrm{~mm}$ particles.

For $3 \mathrm{~mm}$ particles, in horizontal wells with the highest pipe rotation studied $(60 \mathrm{rpm})$, the cuttings concentration increases from $8.7 \%$ to $11.1 \%$ as the drilling rate is increased from $50 \mathrm{ft} / \mathrm{hr}$ to $75 \mathrm{ft} / \mathrm{hr}$ at $120 \mathrm{gpm}$ circulation rate (Figure 18). There is an increase in cutting concentration from $11.1 \%$ to $17.1 \%$ as the rate of penetration is increased from $75 \mathrm{ft} / \mathrm{hr}$ to $100 \mathrm{ft} / \mathrm{hr}$. At $150 \mathrm{gpm}$, the cutting concentration of particles increased from $7.4 \%$ to $14.9 \%$ as the rate of penetration is increased from $50 \mathrm{ft} / \mathrm{hr}$ to $100 \mathrm{ft} / \mathrm{hr}$. A similar effect is noted at $180 \mathrm{gpm}$ where the particle concentration increased from $6.5 \%$ to 13.4 $\%$ as the drilling rate is raised from $50 \mathrm{ft} / \mathrm{hr}$ to $100 \mathrm{ft} / \mathrm{hr}$.

For $8 \mathrm{~mm}$ particles, in horizontal wells with $60 \mathrm{rpm}$ rotation, the cutting concentration increased from $8.8 \%$ to $14 \%$ and then to $17.4 \%$ as ROP value is increased from $50 \mathrm{ft} / \mathrm{hr}$ 
to $75 \mathrm{ft} / \mathrm{hr}$ and to $100 \mathrm{ft} / \mathrm{hr}$, respectively, when a constant flow rate of $120 \mathrm{gpm}$ was used (Figure 19). With a higher flow rate of $150 \mathrm{gpm}$ the cutting concentration increased from $6.2 \%$ to $14.1 \%$ as the drilling rate is increased from $50 \mathrm{ft} / \mathrm{hr}$ to $100 \mathrm{ft} / \mathrm{hr}$. A similar observation occurred at $180 \mathrm{gpm}$. These results show that the cutting concentration in the annulus increased as ROP values are increased.

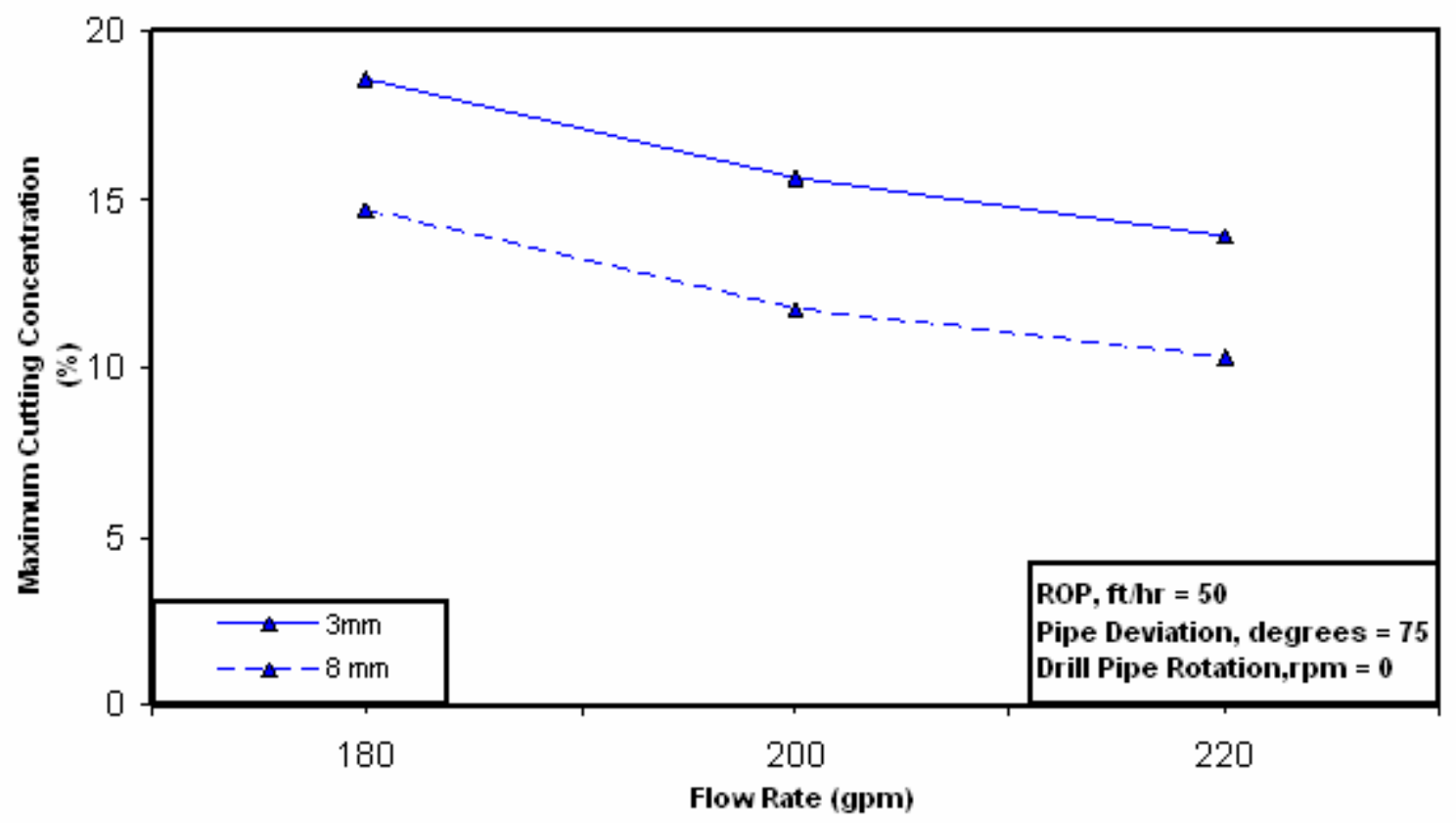

Figure 20: Variation of cutting concentration with flow rate for a deviated well. 


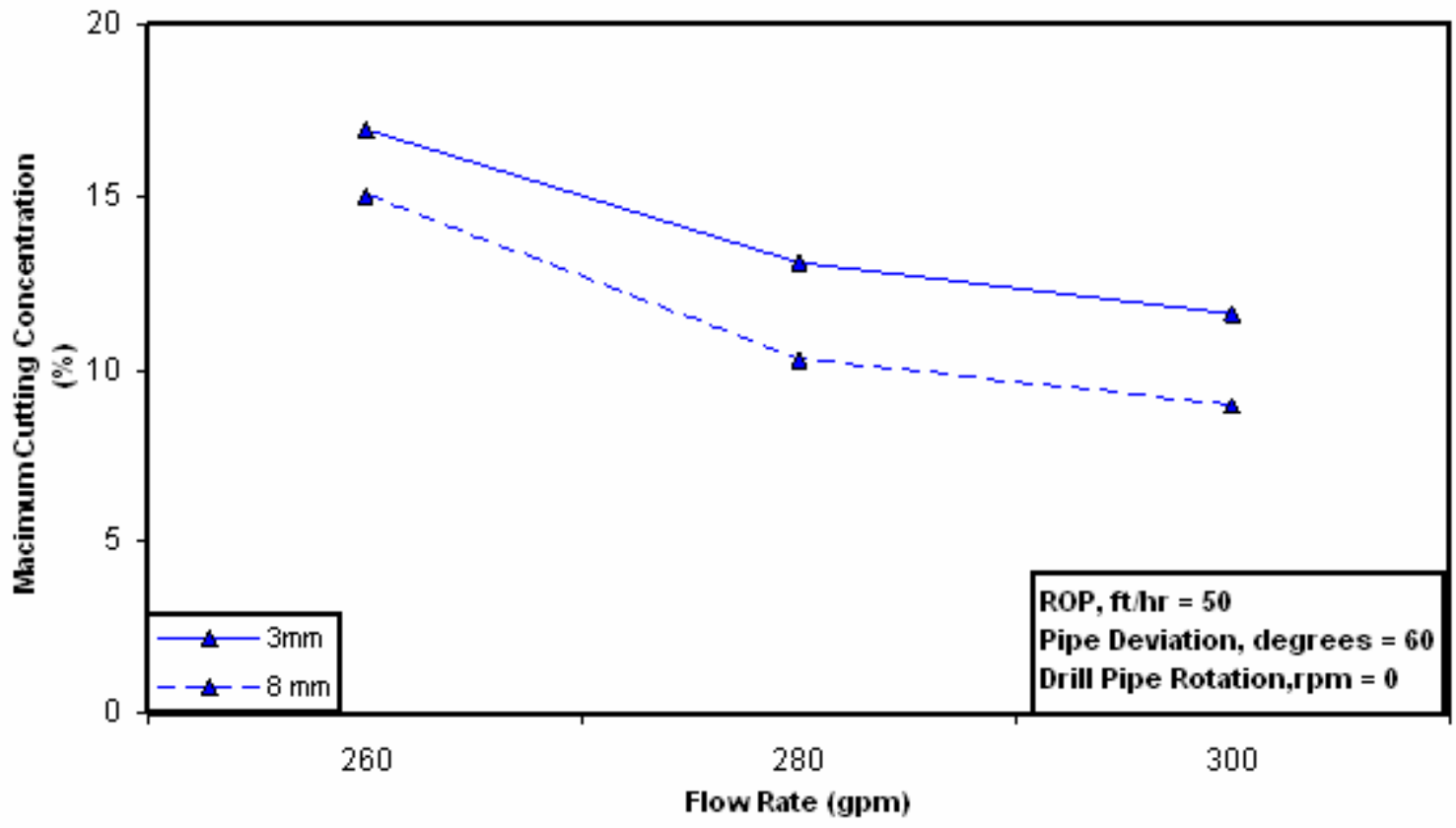

Figure 21: Variation of cutting concentration with. flow rate for a deviated well.

The results for the variation of cutting concentrations with flow rates for small particles $(3 \mathrm{~mm})$ are presented by solid lines and the results for the larger particles $(8 \mathrm{~mm})$ are represented by the dotted lines in Figure 20 and Figure 21, respectively. For wellbores with 75 degree of deviation from vertical, cleaning was facilitated using flow rates ranging from $180 \mathrm{gpm}$ to $220 \mathrm{gpm}$. At $50 \mathrm{ft} / \mathrm{hr}$ ROP, the cutting concentration in the annulus section for $3 \mathrm{~mm}$ particles dropped from $18.6 \%$ to $13.9 \%$ as the flow rate increased from $120 \mathrm{gpm}$ to $180 \mathrm{gpm}$. For $8 \mathrm{~mm}$ particles, the cutting concentration is reduced from $14.7 \%$ to $11.7 \%$ and then to $10.3 \%$ as the flow rate is increased from 180 gpm to $200 \mathrm{gpm}$ and then to $220 \mathrm{gpm}$. Similarly, at a lower angle of deviation (60 degrees), an even higher flow rate range (260 gpm to $300 \mathrm{gpm}$ )is required to help clean the cuttings in the annulus. For a drilling rate of $50 \mathrm{ft} / \mathrm{hr}$, the cutting concentration for 
small particles is reduced from $\quad 17.0 \%$ to $13.1 \%$ as the flow rate is increased from 260 gpm to $280 \mathrm{gpm}$. The cutting concentration is further reduced to $11.6 \%$ as the flow rate is increased to $300 \mathrm{gpm}$. The cutting concentration for large particles $(8 \mathrm{~mm})$ follow a similar trend with reduction from $15.1 \%$ to $10.3 \%$ as the flow rate is increased from 260 gpm to $280 \mathrm{gpm}$. The cutting concentration is further reduced to $8.9 \%$ as the flow rate is increased to $300 \mathrm{gpm}$.

\subsection{Effect of Flow Rates and ROP}

The ROP values together with the hole size ( 6 inch) were used to determine the mass flow rate of particles entering the annular section. Based on volume percentage of injected cuttings, inlet velocity of the particles were calculated. The effects of ROP are given in Figure 14 through Figure 19. In the case of horizontal wells, at any given flow rate, under constant drillpipe rotational speed and same particle size, an increase in the ROP results in an increase in maximum cuttings concentration in the annulus.

Figure 14 through Figure 19 show the observation in a horizontal annulus, for a given cutting size. For the cases studied, an increase in flow rate at a fixed ROP and drill pipe rotation decreases the maximum cutting concentration in the annulus. The effect of flow rates were studied in terms of percent concentration change (Equation 5). Runs conducted with three different flow rates showed that the percent concentration change of the medium size cuttings $(8 \mathrm{~mm}$ ) is slightly larger (about $33 \%$ decrease) than the $3 \mathrm{~mm}$ 
particles (about $20 \%$ decrease). Thus, the hole cleaning was pronounced for the larger cuttings than the smaller cuttings.

\subsection{Effect of Cutting Size}

The effects of cutting sizes for 0,30 and $60 \mathrm{rpm}$ pipe rotation are shown in Figure 22,

Figure 23 and Figure 24, respectively.

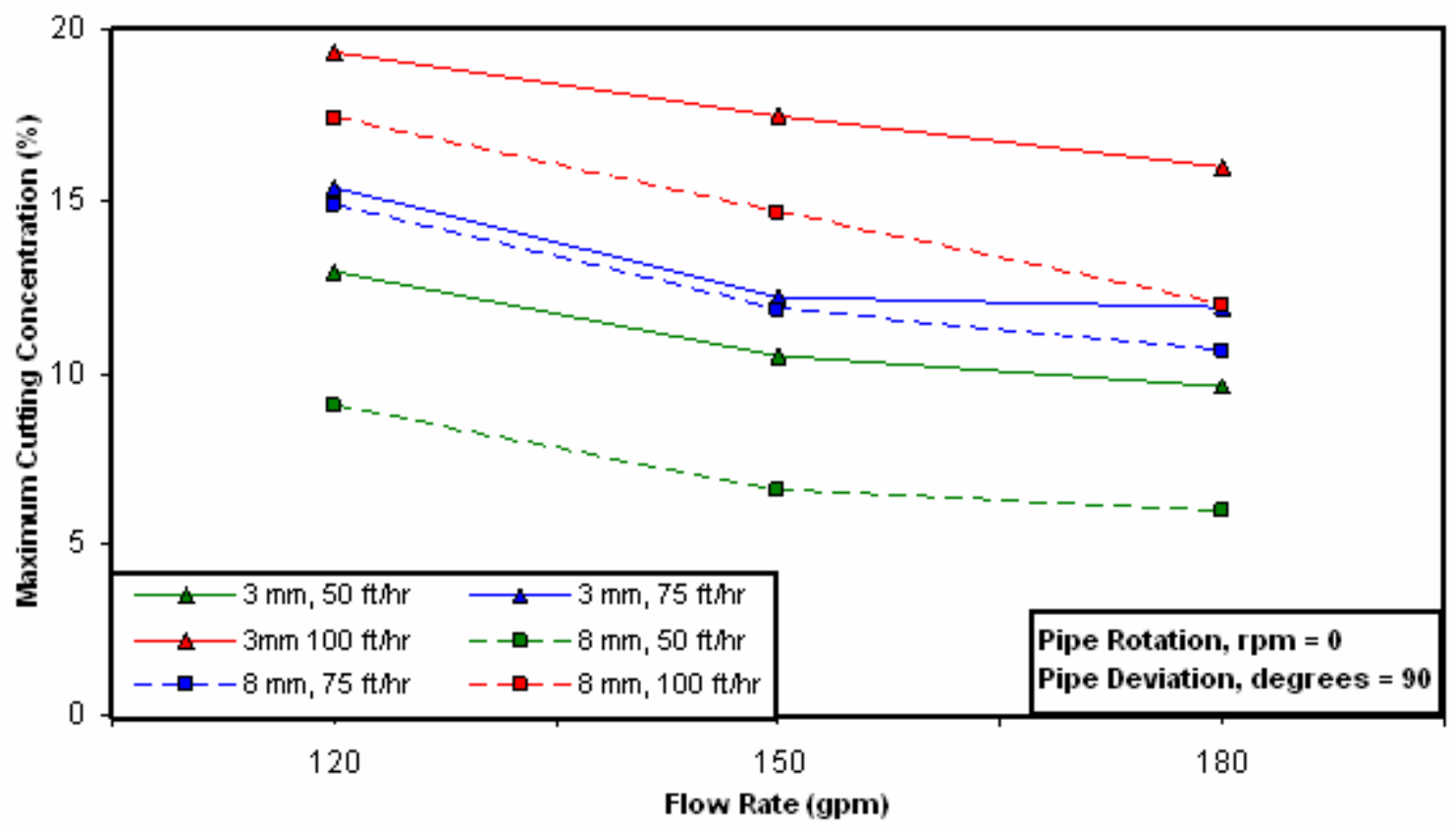

Figure 22: Effect of cutting sizes in horizontal wells without drill pipe rotation. 


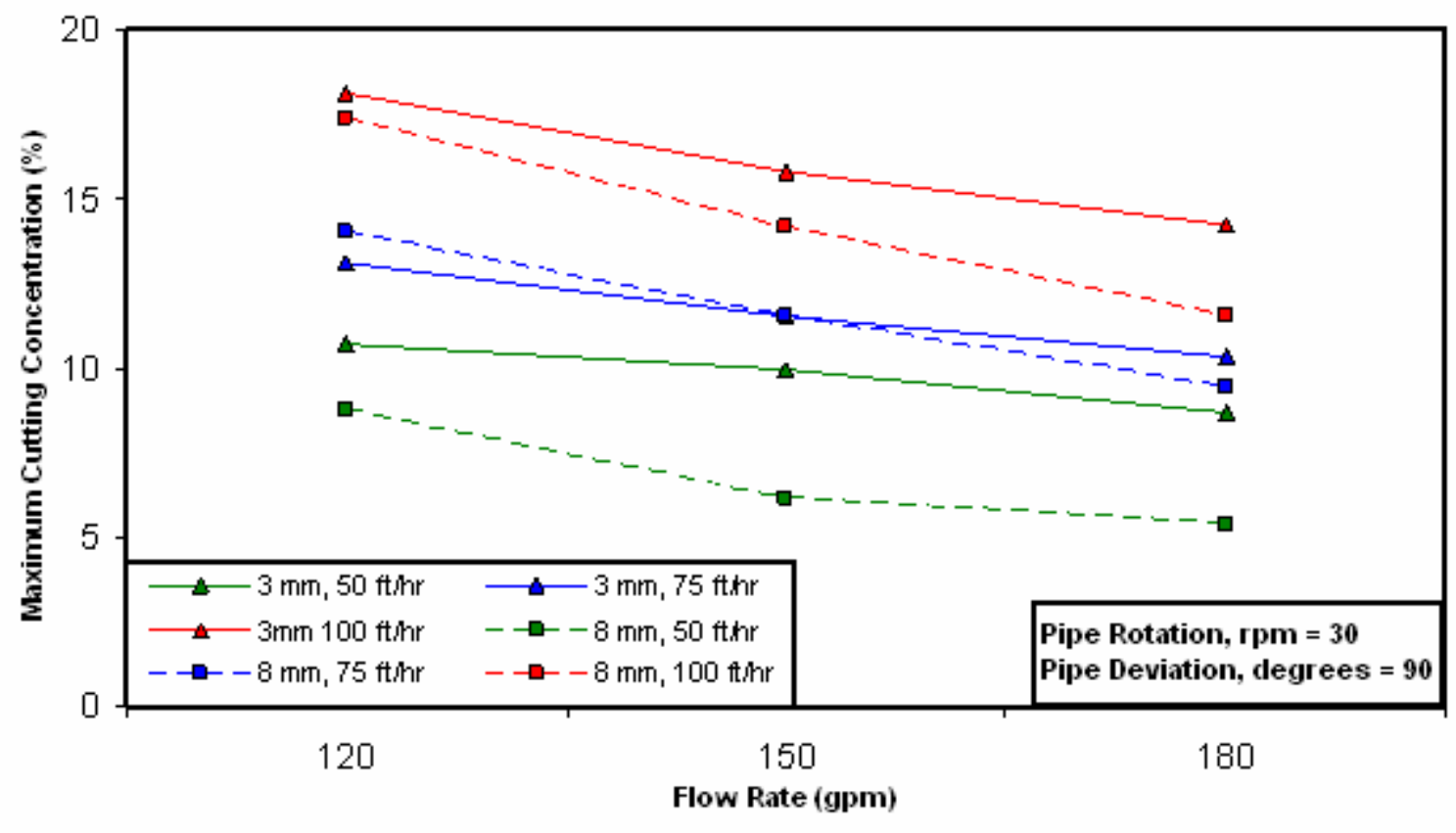

Figure 23: Effect of cutting sizes in horizontal wells at 30 RPM.

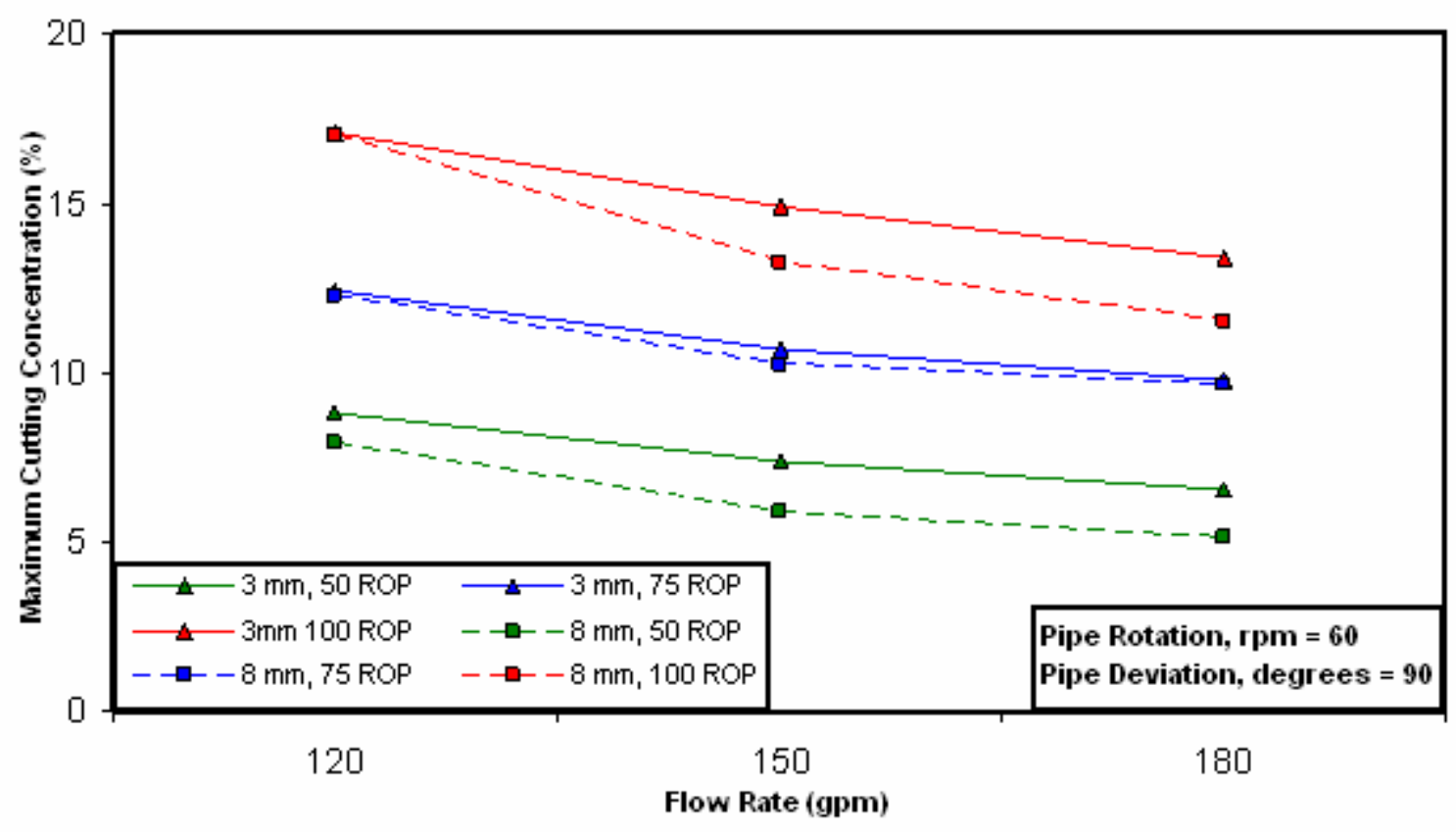

Figure 24: Effect of cutting sizes in horizontal wells at 60 RPM.

The results for the small particles $(3 \mathrm{~mm})$ are presented by solid lines and the results for the larger particles $(8 \mathrm{~mm})$ are represented by the dotted lines. In general, the cutting 
concentration values were smaller for larger particles then smaller particles for all flow rates used in this study. This is the general trend noticed even at different drill pipe rotation rates. This result was unusual but such observations have been made by Duan et. al. ${ }^{[7]}$ especially when water is used to transport smaller particles like the ones used in this work.

\subsection{Effect of Drill Pipe Rotation}

There have been many different views so far with respect to drill pipe rotation. The general consensus is that pipe rotation helps to reduce the volumetric concentration in the annulus for both small and large cutting sizes. Two different pipe rotational speeds were used and the results were compared with results (presented in Figure 25 and Figure 26) when no drillpipe rotation was used. The results for the small particles $(3 \mathrm{~mm})$ are presented by solid lines and the results for the larger particles $(8 \mathrm{~mm})$ are represented by the dotted lines. For all the cases, the efficiency of hole cleaning is improved more significantly for the smaller cuttings where pipe rotation is increased as compared to the larger particles $(8 \mathrm{~mm})$, hence pipe rotation is more useful in transporting smaller particles than larger particles. Thus for smaller particles, instead of increasing fluid velocity, increase in pipe rotation is an effective method to augment cutting's transport. Also, pipe rotation at a fixed velocity can decrease pressure losses as a result of decrease in particle concentration in the annulus. 


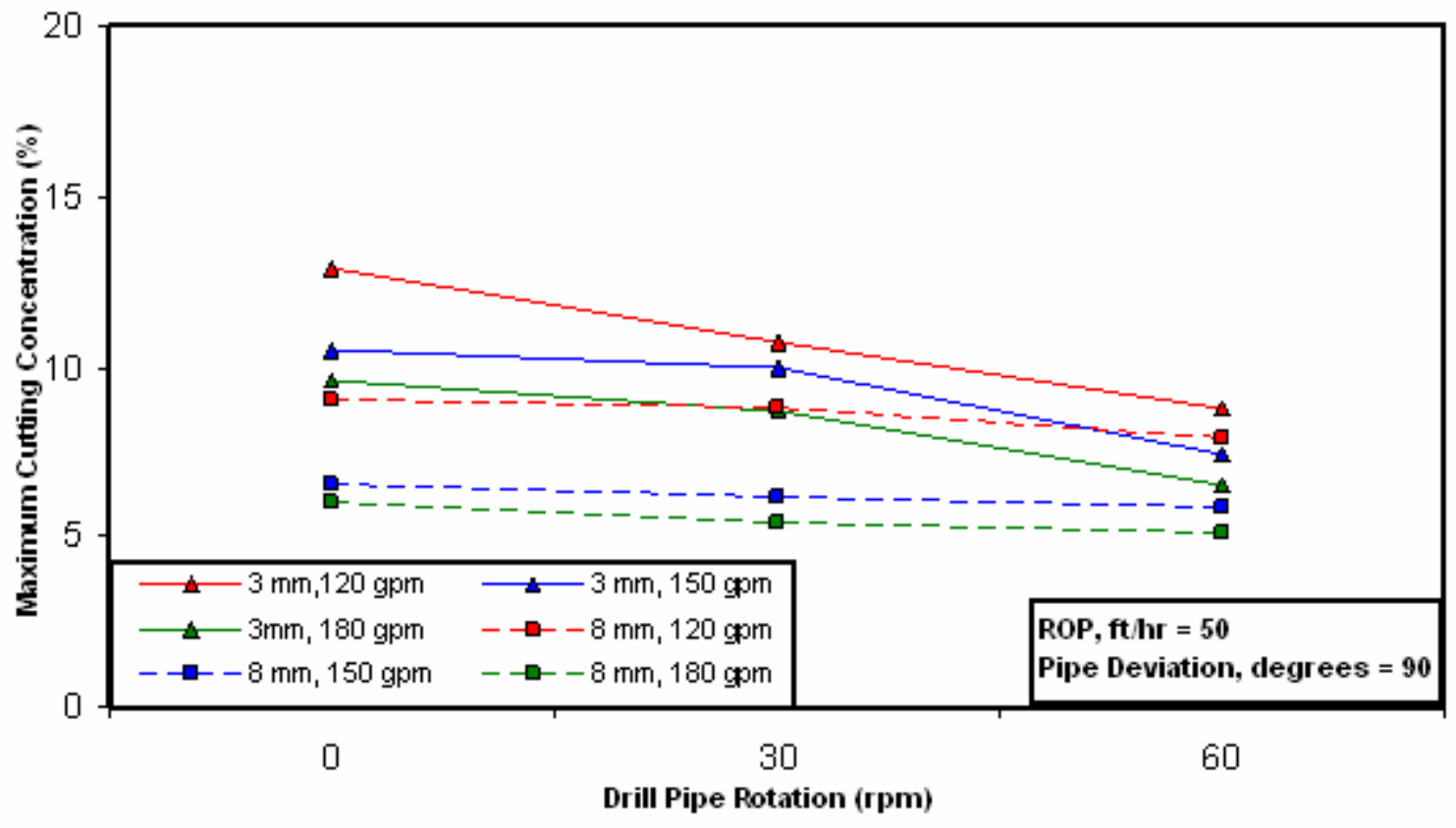

Figure 25: Variation of cutting concentration with drill pipe rotation for a horizontal well, $50 \mathrm{ft} / \mathrm{hr}$ ROP.

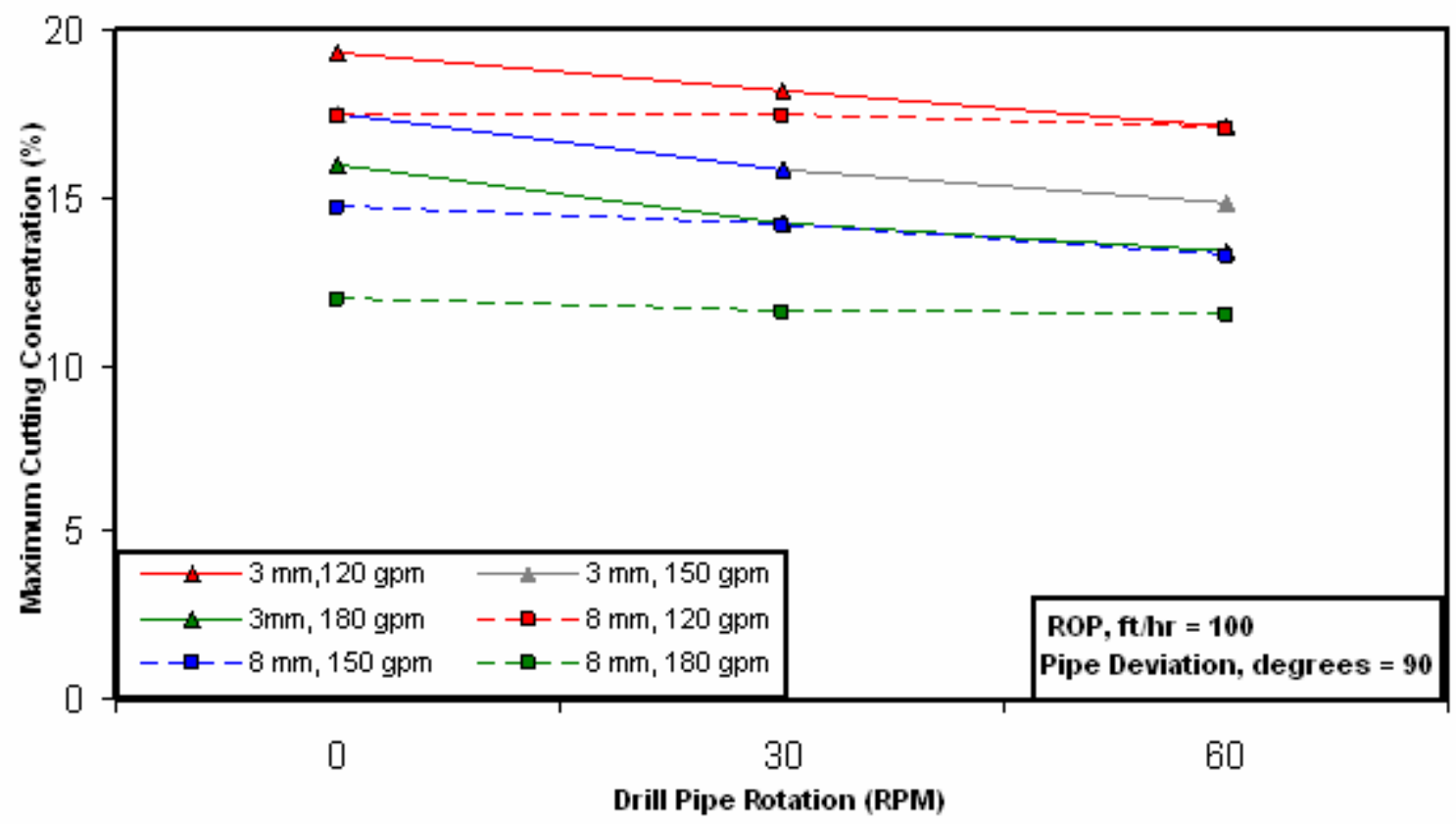

Figure 26: Variation of cutting concentration with drill pipe rotation for horizontal well, $100 \mathrm{ft} / \mathrm{hr}$ ROP. 


\subsection{Effect of Angle of Inclination}

The flow rates studied for horizontal wells (120 to $180 \mathrm{gpm})$ were insufficient to facilitate cutting transport in deviated wells at the angles studied. Hence, runs were conducted at higher fluid velocities of $180 \mathrm{gpm}$ to $220 \mathrm{gpm}$ for 75 degrees deviated wells and 260 to 300 gpm for 60 degrees deviated wells to study the effect of angle of inclination on hole cleaning. The ROP value of $50 \mathrm{ft} / \mathrm{hr}$ was used in all the simulations and pipe rotation was not considered. For both sized particle sizes used in this study, hole cleaning became increasingly difficult as the well angled decreased. 


\section{CHAPTER 5}

\section{CONCLUSIONS AND RECOMMENDATIONS}

\section{$\underline{5.1 \text { Conclusions }}$}

In this research, the effect of five parameters (fluid velocity, ROP, cutting size, drill pipe rotation and angle of inclination) on hole cleaning were studied for horizontal and deviated wells. The hole cleaning fluid used was water. The fluid flow and cutting transportation was modeled using Computational Fluid Dynamics program available at WVU. The work consisted of three different fluid flow rates of 120, 150 and 180 gpm, and three different rates of penetration of 50,75 and $100 \mathrm{ft} / \mathrm{hr}$. Two different cutting sizes were studied, small $(3 \mathrm{~mm})$ particles and large $(8 \mathrm{~mm})$ particles. The drillpipe rotation was taken into account by studying two rotational speeds, 30 and $60 \mathrm{rpm}$, respectively. Also, well deviation was considered for 90 (horizontal well), 75 and 60 degrees. Based on the results, the following conclusions are presented:

- The Eulerian Model in CFD program was used to simulate a cutting transportation in the wellbore successfully. The model was modified to represent the section of the wellbore and was verified against lab data. This model is valid for the two sizes of cuttings studied.

- The cutting concentration decreased with increase in fluid flow rate and increased with increase in drilling rate. Increasing flow rate has a significant cleaning effect for larger particles $(8 \mathrm{~mm})$ as compared to smaller particles. 
- Using water as the drilling fluid, hole cleaning was easier for larger particles as compared to smaller ones.

- Drillpipe rotation improved hole cleaning only marginally for all cutting sizes but the effect is more pronounced for smaller particles.

- Hole deviation has the greatest influence in hole cleaning for the angles studied. As the deviation angle decreases, it becomes harder to clean out particles. The initial flow rates used for horizontal wells lead to blockage of the annular section in deviated wellbores and as a result higher values of flow rate were selected.

- It was observed that the solution becomes unstable for range of flow rates used in this study if cutting concentration exceeds $20 \%$ in the annulus.

\subsection{Recommendations}

- The effect of fluid rheology is an important parameter and should be investigated. Wells nowadays are deeper and the effect of temperature and pressure should be investigated for the non-Newtonian mud.

- The effect of eccentricity should be considered for the drillpipe since it is a major concern in horizontal wells.

- The runs should be conducted using a low density drilling fluid such as aerated mud and foam. 


\section{REFERENCES}

1) Ali M. W.: "A Parametric Study of Cutting Transport in Vertical and Horizontal Wells Using Computational Fluid Dynamics (CFD),” M.S Thesis, West Virginia University, 2002.

2) Kelessidis V.C. and Bandelis G.E., "Flow Pattern and Minimum Suspension Velocity for Efficient Cuttings Transport in Horizontal and Deviated Wells in Coiled-Tube Drilling," SPE 81746, SPE/ICoTA Coiled Tubing Conference, Houston, Texas, April, 8-9, 2003.

3) Zeidler H.U.: "An Experimental Analysis of the Transport of Drilled Particles," SPE 3064, SPEAIME $45^{\text {th }}$ Annual Fall Meeting, Houston, Texas, October, 4-7, 1970.

4 ) Tormen P.H., Iyoho A.W. and Azar J.J.: "An Experimental Study of Cuttings Transport in Directional Wells," SPE 12123, 58 ${ }^{\text {th }}$ SPE Annual Technical Conference and Exhibition, New Orleans, Louisiana, September 25-28, 1994.

5) Okranjni S.S. and Azar J.J.: "The Effects of Mud Rheology on Annular Hole Cleaning in Directional Wells," SPE 14178, SPE Annual Technical Conference and Exhibition, Las Vegas, September, 22-25, 1985.

6) Sifferman T.R. and Becker T.E.: "Hole Cleaning in Full-Scale Inclined Wellbores," SPE 20422, SPE Annual Technical Conference and Exhibition, New Orleans, Lousiana, September, 23-26, 1990.

7) Duan M., Miska S., Yu M., Takach N. and Ahmed R.: "Transport of Small Cuttings in Extended Reach Drilling," SPE 104192, 2006 International Oil \& Gas Conference and Exhibition, Beijing, China, December, 5-7, 2006.

8) Gravignet A. A. and Sobey I. J.: "Model Aids Cuttings Transport Prediction," SPE 15417, 61 ${ }^{\text {st }}$ Annual Technical Conference and Exhibition, New Orleans, L.A., October, 5-8, 1986.

9) Martins A. L. and Santana C. C.: "Evaluation of Cuttings Transport in Horizontal and Near Horizontal Wells-A Dimensionless Approach,” SPE 23643, Second Latin American Petroleum Engineering Conference, II LAPEC, of the Society of Petroleum Engineers, Caracas, Venezuela, March, 8-11, 1992.

10) Doron P. and Barnea D.: "Slurry Flow In Horizontal Pipes-Experimental and Modeling" International Journal of Multiphase Flow, Vol.13, No.4, pg 535-547, 1987. 
11) Martins A.L. and Santana C.C.: "Modeling and Simulation of the Annular Axial Flow of Solid and Non Newtonian Fluid Mixtures,” August, 22-24 1990 III ENCIT, Itapema, Brazil.

12) Pilehvari A. A., Azar J. J and Shirazi S. A.: "State-of-the-Art Cuttings Transport in Horizontal Wellbores," SPE 37079, SPE International Conference on Horizontal Well Technology, Calgary, November, 18-20, 1996.

13) Larsen T.I., Pilehvari A.A. and Azar J.J, "Development of a New Cuttings-Transport Model for High-Angle Wellbores Including Horizontal Wells," SPE 25872, SPE Rocky Mountain Regional Meeting/Low Permeability Reservoir Symposium, Denver, Colorado, April, 26-28, 1993.

14) Peden J.M., Ford J.T. and Oyeneyin M.B.: “Comprehensive Experimental Investigation of Drilled Cuttings Transport in Inclined Wells Including The Effects of Rotation and Eccentricity Drillpipe," SPE 20925, Europe 90, The Haughe, Netherlands, October, 22-24, 1990.

15) Rudi Rubiandini R.S.: "Equation for estimating Mud Minimum Rate for Cuttings Transport in an Inclined-Until-Horizontal Well,” SPE 1172519, 1999 SPE/IADC Middle East Drilling Technology Conference, Dubai, UAE, November, 8-10, 1999.

16) Santana M., Petrobras S. A., Martins A. L. and Sales JR.: “Advances in the Modeling of the Stratified Flow of Drilled Cuttings in High Angle and Horizontal Wells," SPE 39890, International Petroleum Conference and Exhibition of Mexico, Villahermosa, Mexico, March, 5, 1998.

17) Kamp A.M. and Rivero M.: "Layer Modeling for Cuttings Transport in Highly Inclined Wellbores," SPE 53942, SPE Latin American and Caribbean Petroleum Engineering Conference, Caracas, Venezuela, April, 21-23, 1999.

18) Martins A.L., Santana M.L., Campos W. and Gaspari E.F.: "Evaluating the Tranport of Solids Generated by Shale Instabilities in ERW Drilling," SPE 59729-PA, 1998 SPE International Conference of Horizontal Well Technology, Calgary, Canada, November, 1-4, 1998.

19) Cho H., Subhash N. and Samuel O.: "A Three-Segment Hydraulic Model for Cuttings Transport in Horizontal and Deviated Wells," SPE 63269, SPE Annual Technical Conference and Exhibition, Dallas, Texas, October, 1-4, 2000. 
20) Doan Q.T., Oguztoreli M., Masuda Y., Yonezawa T.,Kobayashi A., Naganawa S. and Kamp A.: "Modeling of Transient Cuttings Transport in Underbalanced Drilli.ng (UBD)," SPE 62742, IADC/SPE Asia Pacific Drilling Technology, Kuala Lampur, Malaysia, September, 11-13, 2000.

21) Zhou L.: "Cutting Transport with Aerated Mud in Horizontal Annulus Under Elevated Pressure and Temperature Conditions," Ph D. Thesis, University of Tulsa,, 2004.

22) Massah H.and Oshinowo L.: “Advanced Gas-Solids Multiphase Flow Models Offer Significant Process Improvements," (http://www.fluent.com/solutions/articles/ja112.pdf)

23) Bilgesu H.I, Ali M.W, Aminian K. and Ameri S.: "Computational Fluid Dynamics as a Tool to Study Cutting Transpot in Wellbores,” SPE 78716-MS, SPE Regional Meeting, Lexington, Kentucky, October, 23-25, 2002.

24) Suarez L., Kenyery F. and Asuaje M.: “3D CFD Simulation of Rotary Gas-Seperator Performance Under Two-Phase-Flow Condition," SPE 94959, SPE Lating American and Caribbean Petroleum Engineering Conference, Rio de Janeiro, Brazil, June, 20-23, 2005.

25) Clem N. J., Coronado M. P and Mody R. K.: "Utilizing Computational Fluid Dynamics (CFD) Analysis as Design Tool in Frac-Packing Applications To Improve Erosion Life," SPE 102209, SPE Annual Technical Conference and Exhibition, San Antonia, Texas, September 24-27, 2006.

26) Yusuf A. A.: "The Study of Down-hole Hydro-Cyclone Efficiency in Oil Wells Using Computational Fluid Dynamics”, M.S Thesis, West Virginia University, 2006.

27) Flow Sodeling for Oil and Gas Industries, (http://www.fluent.com/solutions/brochures/oilgas.pdf.)

28) Fluent 6.2 Documentation (http/: Fluent.inc/fluent6.2.1.16/help/index.html). 


\section{APPENDIX A}

\section{A.1 Volume Fraction}

The description of multiphase flow as interpenetrating continua incorporates the concept of phasic volume fractions, denoted here by $\alpha_{\mathrm{q}}$. Volume fractions represent the space occupied by each phase, and the laws of conservation of mass and momentum are satisfied by each phase individually.

The volume of phase $\mathrm{q}, \mathrm{V}_{\mathrm{q}}$, is defined by

$$
\begin{aligned}
& V_{q}=\int_{V} \alpha_{q} d V \\
& \sum_{q=1}^{n} \alpha_{q}=1 \ldots
\end{aligned}
$$

The effective density of phase ' $q$ ' is

$$
\hat{\rho}_{q}=\alpha_{q} \rho_{q}
$$

\section{A.2 Conservation Equations}

For mass conservation the continuity equation for phase $\mathrm{q}$ is

$$
\frac{\partial}{\partial t}\left(\alpha_{q} \rho_{q}\right)+\nabla \cdot\left(\alpha_{q} \rho_{q} \vec{v}_{q}\right)=\sum_{p=1}^{n}\left(\dot{m}_{p q}-\dot{m}_{q p}\right)+S_{q}
$$

Where $\vec{v}_{q}$ is the velocity of phase $\mathrm{q}$ and $\dot{m}_{p q}$ characterizes the mass transfer from the $\mathrm{p}^{\text {th }}$ to the $\mathrm{q}^{\text {th }}$ phase, and $\dot{m}_{q p}$ characterizes the mass transfer from $\mathrm{q}$ phase to $\mathrm{p}$ phase, and provides means to specify these mechanisms separately. By default, the source term $S_{q}$ 
on the right-hand side of Equation 8 is zero, but users can specify a constant or userdefined mass source for each phase.

The momentum balance for phase q yields

$$
\begin{aligned}
& \frac{\partial}{\partial t}\left(\alpha_{q} \rho_{q} \vec{v}_{q}\right)+\nabla \cdot\left(\alpha_{q} \rho_{q} \vec{v}_{q} \vec{v}_{q}\right)=-\alpha_{q} \nabla p+\nabla \cdot \bar{\tau}_{q}+\alpha_{q} \rho_{q} \vec{g}+\sum_{p=1}^{n}\left(\vec{R}_{p q}+\dot{m}_{p q} \vec{v}_{p q}-\dot{m}_{q p} \vec{v}_{q p}\right)+ \\
& \left(\vec{F}_{q}+\vec{F}_{l i f t, q}+\vec{F}_{l i f t, v m}\right)
\end{aligned}
$$

where $\bar{\tau}_{q}$ is the $\mathrm{q}^{\text {th }}$ phase stress-strain tensor

$$
\overline{\bar{\tau}}_{q}=\alpha_{q} \mu_{q}\left(\nabla \vec{v}_{q}+\nabla \vec{v}_{q}^{T}\right)+\alpha_{q}\left(\lambda_{q}-\frac{2}{3} \mu_{q}\right) \nabla \cdot \vec{v}_{q} \overline{\bar{I}}
$$

Here $\mu_{q}$ and $\lambda_{q}$ are the shear and bulk viscosity of phase $\mathrm{q}, \vec{F}_{q}$ is an external body force, $\vec{F}_{l i f t, q}$ is a lift force, $\vec{F}_{l i f t, v m}$ is a virtual mass force, $\vec{R}_{p q}$ is an interaction force between phases, and $\mathrm{p}$ is the pressure shared by all phases. $\vec{v}_{p q}$ is the interphase velocity, defined as follows. If $\dot{m}_{p q}>0$ (i.e., phase $\mathrm{p}$ mass is being transferred to phase $\mathrm{q}$ ), $\vec{v}_{p q}=\vec{v}_{p}$; if $\dot{m}_{p q}<0$ (i.e., phase $\mathrm{q}$ mass is being transferred to phase $\mathrm{p}$ ), $\vec{v}_{p q}=\vec{v}_{q}$. Likewise, if $\dot{m}_{q p}>0$ then $\vec{v}_{q p}=\vec{v}_{q}$, if $\dot{m}_{q p}>0$ then $\vec{v}_{q p}=\vec{v}_{p}$.

Equation 9 must be closed with appropriate expressions for the interphase force $\vec{R}_{p q}$. This force depends on the friction, pressure, cohesion, and other effects, and is subject to the 
conditions that $\vec{R}_{p q}=-\vec{R}_{q p}$ and $\vec{R}_{q q}=0$. Fluent uses a simple interaction term of the following form:

$$
\sum_{p=1}^{n} \vec{R}_{p q}=\sum_{p=1}^{n} \vec{K}_{p q}\left(\vec{v}_{p}-\vec{v}_{q}\right)
$$

where $\vec{K}_{p q}=\left(\vec{K}_{q p}\right)$ is the interphase momentum exchange coefficient

For multiphase flows, Fluent can include the effect of lift forces on the secondary phase particles. These lift forces act on a particle mainly due to velocity gradients in the primary-phase flow field. The lift force will be more significant for larger particles, but the Fluent model assumes that the particle diameter is much smaller than the interparticle spacing. Thus, the inclusion of lift forces is not appropriate for closely packed particles or for very small particles.

The lift force acting on a secondary phase $\mathrm{p}$ in a primary phase $\mathrm{q}$ is given by

$$
\vec{F}_{l i f t, q}=-0.5 \rho_{q} \alpha_{q}\left(\vec{v}_{q}-\vec{v}_{p}\right) \times\left(\nabla \times \vec{v}_{q}\right)
$$

The lift force $\vec{F}_{l i f t, q}$ will be added to the right-hand side of the momentum equation for both phases $\left(\vec{F}_{\text {lift }, q}=\vec{F}_{\text {lift }, p}\right)$. In most cases, the lift force is insignificant compared to the drag force, so there is no reason to include this extra term. If the lift force is significant (e.g., if the phases separate quickly), it may be appropriate to include this term. By default, $\vec{F}_{l i f t, q}$ is not included. The lift force and lift coefficient can be specified for each pair of phases, if desired. In our case we used the coefficient as 0.5 . The virtual mass 
forces are not included in our model setup. The volume fraction for each phase is given by

$$
\frac{1}{\rho_{\tau q}}\left(\frac{\partial}{\partial t}\left(\alpha_{q} \rho_{q}\right)+\nabla \cdot\left(\alpha_{q} \rho_{q} \vec{v}_{q}\right)=\sum_{p=1}^{n}\left(\dot{m}_{p q}-\dot{m}_{q p}\right)\right)
$$

where $\rho_{\tau q}$ is the phase reference density, or the volume averaged density of the $\mathrm{q}^{\text {th }}$ phase in the solution domain.

\section{A.3 Solution Method in Fluent}

For Eulerian multiphase calculations, Fluent uses the Phase Coupled SIMPLE (PCSIMPLE) algorithm for the pressure-velocity coupling. PC-SIMPLE is an extension of the SIMPLE algorithm to multiphase flows. The velocities are solved coupled by phases, but in a segregated fashion. The block algebraic multigrid scheme employed by the coupled solver is used to solve a vector equation formed by the velocity components of all phases simultaneously. Then, a pressure correction equation is built based on total volume continuity rather than mass continuity. Pressure and velocities are then corrected so as to satisfy the continuity constraint.

For incompressible multiphase flow, the pressure-correction equation takes the form

$$
\sum_{k=1}^{n} \frac{1}{\rho_{r k}}\left\{\frac{\partial}{\partial t} \alpha_{k} \rho_{k}+\nabla \cdot \alpha_{k} \rho_{k} \vec{v}^{f}{ }_{k}+\nabla \cdot \alpha_{k} \rho_{k} \vec{v}^{*}{ }_{k}-\left(\sum_{l=1}^{n}\left(\dot{m}_{l k}-\dot{m}_{k l}\right)\right)\right\}=0
$$

where $\rho_{r k}$ is the phase reference density for the $\mathrm{k}^{\text {th }}$ phase (defined as the total volume average density of phase $\mathrm{k}), \vec{v}^{f}{ }_{k}$ is the velocity correction for the $\mathrm{k}^{\text {th }}$ phase, and $\vec{v}^{*}{ }_{k}$ is the 
value of $\vec{v} k$ at the current iteration. The velocity corrections are themselves expressed as functions of the pressure corrections.

The volume fractions are obtained from the phase continuity equations. In discretized form, the equation of the $\mathrm{k}^{\text {th }}$ volume fraction is

$$
\alpha_{p, k} \alpha_{k}=\sum_{n b}\left(a_{n b, k} \alpha_{n b, k}\right)+b_{k}=R_{k}
$$

In order to satisfy the condition that all the volume fractions sum to one, the following equation must be valid

$$
\sum_{k=1}^{n} \alpha_{k}=1
$$

